\title{
The LEGATO cross-disciplinary integrated ecosystem service research framework: an example of integrating research results from the analysis of global change impacts and the social, cultural and economic system dynamics of irrigated rice production
}

\author{
Joachim H. Spangenberg ${ }^{1,2}$ (1) - Alexis L. Beaurepaire ${ }^{3}$ Erwin Bergmeier ${ }^{4} \cdot$ Benjamin Burkhard $^{5,6} \cdot$ Ho Van Chien $^{7}$. \\ Le Quoc Cuong ${ }^{7}$. Christoph Görg ${ }^{8}$. Volker Grescho ${ }^{1,9} \cdot$ Le Huu Hai $^{10}$. Kong Luen Heong ${ }^{11,12}$. Finbarr G. Horgan ${ }^{11}$. \\ Stefan Hotes $^{13}$. Anika Klotzbücher ${ }^{1,14}$. Thimo Klotzbücher ${ }^{14}$ • Ingolf Kühnn ${ }^{1,15,16}$. Fanny Langerwisch ${ }^{17}$. \\ Glenn Marion ${ }^{18}$. Robin F. A. Moritz ${ }^{3,15}$. Quynh Anh Nguyen ${ }^{19}$. Jürgen Ott ${ }^{1,20}$. Christina Sann ${ }^{21}$. Cornelia Sattler ${ }^{1}$. \\ Martin Schädler ${ }^{1} \cdot$ Anja Schmidt $^{1} \cdot$ Vera Tekken ${ }^{22} \cdot$ Truong Dao Thanh $^{19} \cdot$ Kirsten Thonicke $^{17} \cdot$ Manfred Türke $^{16,23,24}$. \\ Tomáś Václavík $^{25,26} \cdot$ Doris Vetterlein $^{14,27} \cdot$ Catrin Westphal ${ }^{28} \cdot$ Martin Wiemers $^{1} \cdot$ Josef Settele $^{1,16,29}$
}

Received: 6 March 2017 / Revised: 24 November 2017 / Accepted: 29 November 2017 / Published online: 20 December 2017

(c) The Author(s) 2017. This article is an open access publication

\begin{abstract}
In a cross-disciplinary project (LEGATO) combining inter- and transdisciplinary methods, we quantify the dependency of rice-dominated socio-ecological systems on ecosystem functions (ESF) and the ecosystem services (ESS) the integrated system provides. In the collaboration of a large team including geo- and bioscientists, economists, political and cultural scientists, the mutual influences of the biological, climate and soil conditions of the agricultural area and its surrounding natural landscape have been analysed. One focus was on sociocultural and economic backgrounds, another on local as well as regional land use intensity and biodiversity, and the potential impacts of future climate and land use change. LEGATO analysed characteristic elements of three service strands defined by the Millennium Ecosystem Assessment (MA): (a) provisioning services: nutrient cycling and crop production; (b) regulating services: biocontrol and pollination; and (c) cultural services: cultural identity and aesthetics. However, in line with much of the current ESS literature, what the MA called supporting services is treated as ESF within LEGATO. As a core output, LEGATO developed generally applicable principles of ecological engineering (EE), suitable for application in the context of future climate and land use change. EE is an emerging discipline, concerned with the design, monitoring and construction of ecosystems and aims at developing strategies to optimise ecosystem services through exploiting natural regulation mechanisms instead of suppressing them. Along these lines LEGATO also aims to create the knowledge base for decision-making for sustainable land management and livelihoods, including the provision of the corresponding governance and management strategies, technologies and system solutions.
\end{abstract}

Keywords Ecosystem services · Transdisciplinary research $\cdot$ Paddy rice agriculture $\cdot$ Biodiversity $\cdot$ Rural development . Culture

\section{Introduction}

LEGATO is the acronym for the project 'Land-use intensity and Ecological enGineering-Assessment Tools for risks and Opportunities in irrigated rice based production systems', funded by the German Ministry of Research and Education under its Land Management research program (see Settele et al., this issue).

Joachim H. Spangenberg

Joachim.Spangenberg@ufz.de

Extended author information available on the last page of the article
Society-nature interaction is a process in which a symbolic, cultural sphere (a system of recursive communication that may be denoted as "culture") interacts with the biophysical sphere; that is, a system of physical objects that interact through flows of energy, substances or materials (Haberl et al. 2009, p. 1801) 
The rapid changes in landscape management and land use in South East Asia (SEA) in recent decades (Fox and Vogler 2005), driven by forces of local and global change such as population growth, urbanisation, technological progress (e.g. mechanisation and high yielding crop varieties) and climate change, provide opportunities for improving livelihoods, but also produce threats, e.g. to food security (Ericksen et al. 2009; Godfray et al. 2010). Exploiting opportunities and establishing early warning systems for emerging risks is a plausible if not mandatory demand in this situation.

The LEGATO project has been designed to provide assessment tools for risks and opportunities in irrigated rice-based production systems. Due to the many and diverse linkages among ecological and social components of agricultural ecosystems, the challenges of developing meaningful system-scale analysis and target setting are amplified and trade-offs are acute. While for many single-sector ecosystem management situations targets and mechanisms for setting them are well established, this is much less the case for entire coupled socio-ecological systems, despite the undisputed urgency of developing appropriate approaches (Levin et al. 2015). To provide decision makers, from farmers to administrators and politicians, with the opportunity to explicitly consider how management options propagate throughout the human and bio-chemo-physical (for short in this paper: biophysical) domains of ecosystems, analyses suitable as basis for policy recommendations have to open the "black box", revealing the feedback mechanisms, positive and negative, between processes and dynamics in the interacting social, economic, ecological and cultural dimensions establishing the complex evolving socio-environmental metasystem (Spangenberg 2014). This paper is, to the best of our knowledge, the first to describe the functional interactions between key components within the social-ecological system analysed in a harmonised fashion (for a definition of terms see the glossary).

This requires cross-disciplinary research approaches (a summary term for multi-, inter- and transdisciplinary research, see Morton et al. 2015) based on a broad set of disciplines from natural to social and cultural sciences to collaborate among and between each other and with stakeholders within a coherent joint framework. Economics and political science must analyse the processes leading to certain management decisions, human and cultural sciences explain not only if, or why not, such decisions are effectively implemented (Rosenthal et al. 2014), but also describe how modernisation processes, including commodification and urbanisation, erode indigenous knowledge about sustainable, low input agriculture, while natural sciences have to analyse how beneficial such practices could be from an environmental perspective (Seppelt et al. 2012).

Such a joint process requires integrating approaches, methods and knowledge across disciplines that are often based on different world views. The goal here is to demonstrate the benefits of such collaboration and show how progress can be made towards a synthesis by stepwise integration of multi-disciplinary results produced from studying multiple aspects of complex, dynamically changing agricultural landscapes (Förster et al. 2015) within a transdisciplinary project design. We illustrate the process drawing on the example of the transdisciplinary LEGATO project, and its studies of the ecosystem services (ESS) provided by rice agro-ecosystems in SEA (Settele et al. 2013, 2015), their generation and use.

ESS is a boundary concept (Görg and Aicher 2014; Hertz and Schlüter 2015) that is yet to develop as a theory, extending across disciplinary boundaries with so far diverging interpretations of its elements and differing terminology across disciplines and schools of thought (Mollinga 2010; Hauck et al. 2014). Thus, this paper builds upon existing ESS concepts to develop a joint transdisciplinary framework to aid communication, minimise misunderstandings, promote coherent use of terminology and enable synthesis of results - both within large transdisciplinary research projects, such as LEGATO, and in their external communication. Thus, the proposed framework should lead to improved management/stewardship of ESS (Boyd and Banzhaf 2007). It could also serve as a model for knowledge integration within other complex transdisciplinary projects studying ESS and related issues.

To achieve this goal, the paper follows the structure of the "ecosystem service cascade" (Potschin and Haines-Young 2011; Haines-Young et al. 2012), modified to also take human influences into account (Spangenberg et al. 2014a, b); such conceptual models have proven useful for understanding socio-environmental systems and synthesising diverse scientific information (Levin et al. 2015). It describes the co-generation of human benefits, starting with the analysis of biodiversity and ecosystem processes and continuing to biodiversity-ecosystem function (BEF) research, one focus of our work in LEGATO.

The analysis of these links is combined with social science results to understand the factors influencing the ecosystem service potential ESP (the use value potential attributed by society to an ecosystem function ESF) and then the generation of ESS and ecosystem benefits ESB. In summary, human agency and ESF co-determine the potentials identified, the services provided and the benefits enjoyed, and both must be analysed jointly to derive suggestions for improved land management which will lead to enhanced ESB and therefore will be likely to indeed be implemented effectively by stakeholders.

The first step of generating ESS and the benefits they provide is recognising the usability of ecosystem structures, processes and outputs, e.g. attributing a certain use option to a piece of land (Spangenberg et al. 2014a). This use value 
attribution transforms the ecosystem functions (ESF) into ecosystem service potentials (ESP) like arable land, construction materials and sites, or nature conservation area. By investing physical resources, energy and labour, and frequently money as a means to provide them, agents mobilise (part of) the ESP (in these examples, by ploughing, cutting/harvesting and building, or-less so in wet rice ecosystems - by fencing). Cultural and ethical or social norms, economic and legal constraints, and trade-offs between different ESP limit mobilisation (McShane et al. 2011). In some regions, such norms will be codified by legislation or regulations, while in other instances, norms may not be codified, necessitating additional social science research (Levin et al. 2015).

Many ESS are known to local stakeholders, but while scientists frequently describe ESS are as nature's free gift to humankind, the beneficiaries often do not perceive them as free gifts, but as a result of co-production of humans and nature (Bengtsson 2015; Scholte et al. 2015; Jones et al. 2016). For both provisioning and cultural ESS, beneficiaries tend not to perceive themselves as passive recipients of "goods" or "benefits", but as actively searching, and pursuing the generation of such services and their benefits (de Oliveira and Berkes 2014; own observations of several coauthors). Regulating ESS have often been experienced by stakeholders as natural conditions rather than as nature's services, in so far as they do not require any human action beyond recognition by the beneficiaries, although they can often be enhanced by human intervention. Cultural ESS play a special role as they can be attributed to the objects representing the ESS, to the resulting ESB, but also to the processes of generating them, in the context of rice agriculture from joint decisions on the use of ecosystems to land preparation, harvesting, milling and cooking. Thus, different ESS are used in different ways (e.g. passively appreciated or actively enhanced in the case of regulating services, consumed for the provisioning services, and activated/actively enjoyed for sociocultural ones) to satisfy human needs and/ or wants and thus to contribute to human welfare.

The ESS are appropriated to be directly consumed (fruits are picked), exploited to provide other goods and services (grain is harvested and processed, producing bread, rice cake, etc.) or marketed, resulting in (mostly monetary) income. Each of these options provides ecosystem benefits (ESB), albeit different ones (food, income); only in the latter case monetary values do play a decisive role (Spangenberg et al. 2014b; Spangenberg and Settele 2016). Human communities including the LEGATO rice farmers may have lived with (and unknowingly depended on) amenities provided by ecosystems for a long time, without necessarily perceiving them as services.

In the terminology used here, landscape management can be described as a series of anthropogenic interventions managing ecosystem functions, processes and outputs for the benefits of humans; however, it is society (or powerful parts thereof), not scientists, that define what are desired social benefits. So it is no surprise that the attribution, appropriation and the mobilisation phases are the ones when most environmental conflicts arise, be it for the destruction of the local environment, or the exclusion of people from the land they traditionally own or use. Other conflicts arise over the distribution of benefits from the mobilisation. Often these conflicts can be described as power struggles over the rights first to define the ESP on the basis of given ESF and then to mobilise the ESP and appropriate the kinds of ESS the local community or the farm workers wishes to enjoy as ESB, versus the services land owners, investors and/or governments intend to mobilise, appropriate and enjoy.

The complexity of the socio-environmental system makes any attempt to characterise the LEGATO results by cardinal measures of welfare futile. The fact that individuals differ in the values they hold implies that they will also differ in how they value benefits and trade-offs between different options. This demands a different approach, integrating diverse aspects and levels of ecosystem functioning and welfare generation. This is no shortcoming: stakeholders tend to prefer different metrics for different kinds of benefits, like money value for the results of marketing provisioning services and biophysical and social metrics for all other benefits (Ruckelshaus et al. 2015). Unlike welfare quantification, observing market mechanisms and their impacts is important to understand the dynamics of the socio-environmental system. For instance, in the case of undersupply of rice or any other ESB, price will tend to rise, creating a strong incentive to increase the volume available. The usual way of increasing the volume is to manage the ecosystem in a way that the ecosystem functions providing the basis for the service provision are strengthened. This, however, causes biophysical changes and may impinge on other ESS, valued or not. These feedbacks of market demand on landscape management and the state of the environment are one of the reasons why in LEGATO biophysical analyses are combined with sociocultural and economic assessments.

Different Work Packages in LEGATO address different "blind spots" of the processes linking ESF to ESB with different methods and based on different bodies of theory. Due to length restrictions applying even to an extended paper, it is impossible to comprehensively describe the theoretical backgrounds, methods, results and their interpretation for all modules in LEGATO; instead, a choice had to be made. In the fields of cultural and economic analysis, some more conceptual background is provided, as many readers may not be familiar with the respective theoretical background and the methodological approaches. In exemplary cases methods and results from scientific analyses are presented, as 


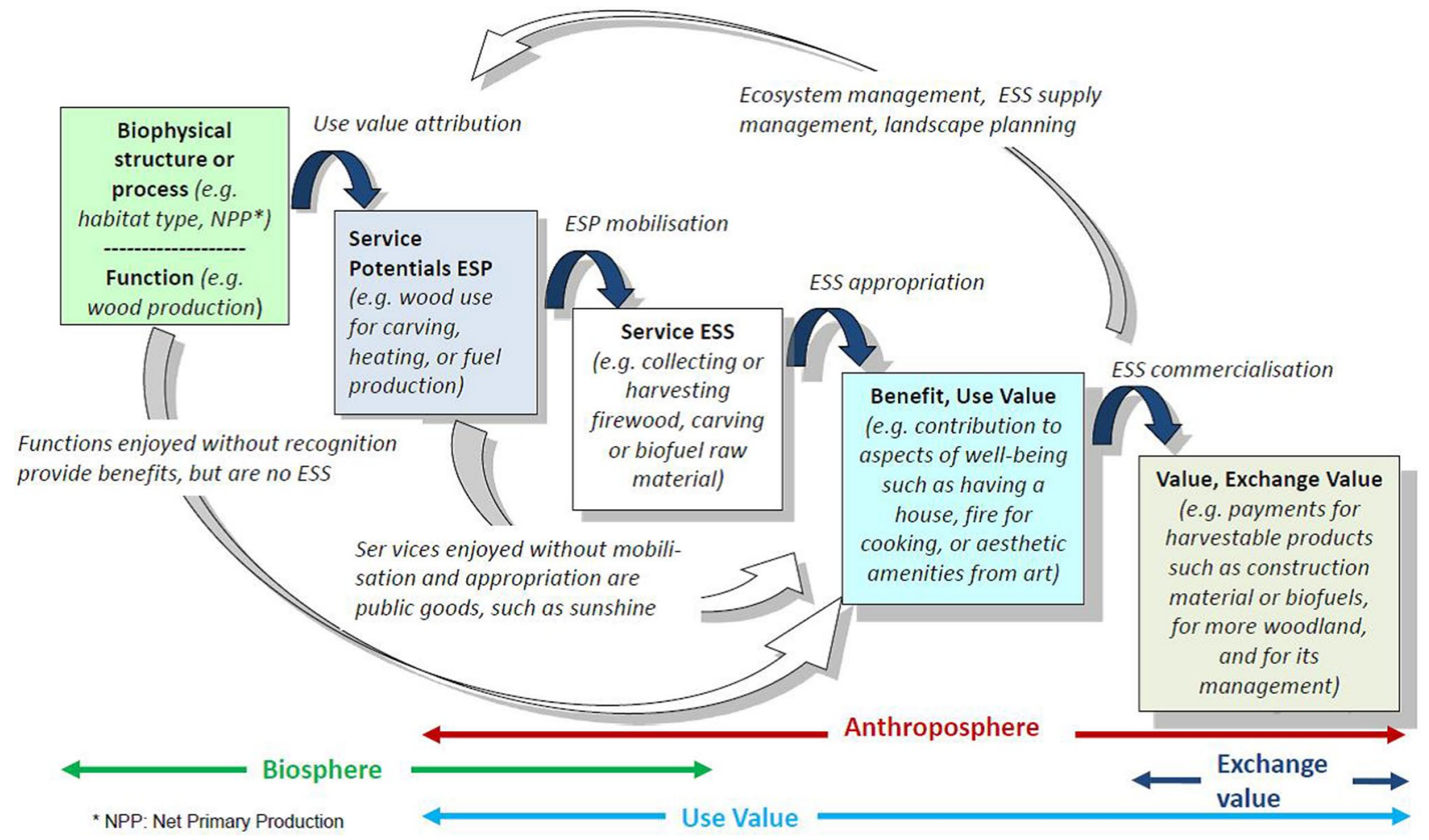

Fig. 1 Most ESS are generated by human agency using biospheric materials and functions; ESS which are non-rival and non-excludable are public goods. ESF enjoyed without recognising their origin in the ecosystem may provide ecosystem benefits ESB, but are not consid-

illustrations of up-to-date fieldwork, desktop analysis and conceptual developments.

In the second section the overall research method is described and the LEGATO research landscapes are introduced. The third section applies the ESS cascade shown in Fig. 1 as a conceptual model within which to integrate the multi-disciplinary study of bio-chemo-geo-genic inputs, processes and elements (for short: ecogenic factors), and influences originating from human activities (anthropogenic factors). The individual steps are described and graphically illustrated in a standardised manner. This provides the basis for the discussion and the conclusions drawn regarding project design and conduct in the last section of the paper.

\section{Research approaches: combining ecogenic and anthropogenic factors}

\section{Methods}

A core task of LEGATO (Settele et al. 2013, 2015, this issue) is to analyse and (where possible) quantify ecosystem functions (ESF) in irrigated rice landscapes of South East Asia and the multiple ecosystem services (ESS) dependent ered as ESS since they have not been recognised as such by the beneficiaries. From Spangenberg et al. (2014a), modified after Potschin and Haines-Young (2011)

on them. The project is unique in analysing (1) provisioning services (harvest, nutrient provision), (2) regulating services (biological pest control and pollination-the latter, as LEGATO is not restricted to study rice fields but deals with rice-dominated landscapes and the impact of land use in rice on ESF/ESS in the landscape) and (3) cultural services such as aesthetics and identity, and their interactions.

The studies conducted within LEGATO combine both natural and social science elements, analysing ecosystem properties, dynamic interactions of ecosystem elements, structures and natural processes, and interactions with anthropogenic influences (e.g. farming practices). These elements and their interactions (for instance, soil composition, natural weathering, the activities of decomposers) bring about the actual ESF, nutrient cycling, as an emergent property of the ecosystem. Recognised as usable/ exploitable, nutrient cycling (like such biophysical functions in general) is the basis for the societal use value attribution defining the ESP, in this case "soil fertility". By analysing system dynamics, natural science is able to identify theoretically sustainable levels and patterns of ESP use, understood here as modes of use not overburdening the ecosystem's capacity to deliver ESS, e.g. the use intensity permissible in rice terraces without running the risk 


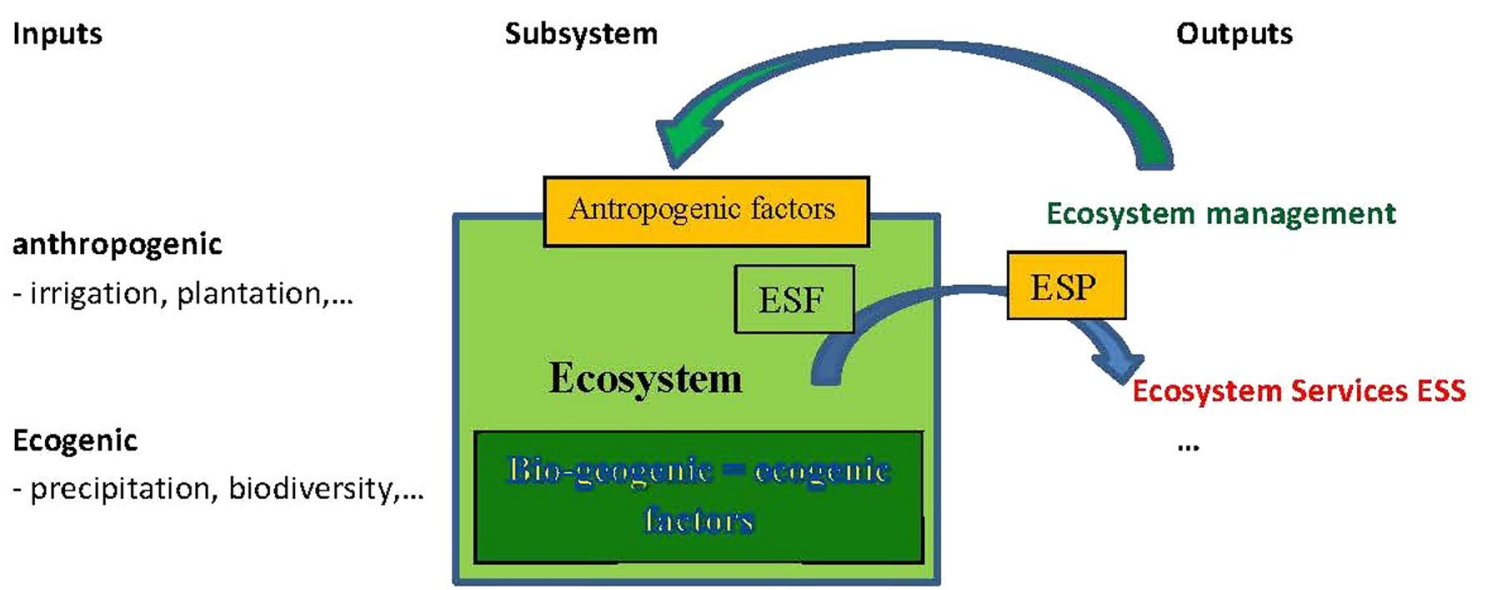

Fig. 2 The ecosystem and the internal and external factors influencing its development

of degrading them. Different but also effective restrictions in the social system are analysed by social and cultural sciences, like traditions, ownership structures or incentives. All taken together, such an analysis is a complex technical and scientific challenge which to date can only be undertaken with partial success and often with a high level of uncertainty. Society's institutional system (local or regional administration, farmers' self-organisation, etc.) is then called upon to decide if the system configuration and its potential changes are concerns serious enough to justify the efforts necessary to avoid it, for instance by investing time, work and resources in maintaining and restoring rice terraces to maintain ecosystem functions and thus the services provided by mobilising the ESP based on the ESF. This can be a very different ESP than the initially cultivated one-in the case of rice terraces the aesthetic value (ESP) attracting tourists (EES) which generate income (ESB).

To provide an accessible introduction to this complex process, Fig. 2 shows a standardised schematic description, naming key inputs/influences from ecogenic and anthropogenic domains which have an impact on ecosystem functions. It illustrates that to understand ecosystem functions and predict future system behaviour, e.g. under different management methods like ecological engineering or under climate change, it is necessary to take the interactions of factors from both domains into account (see Fig. 2).

The scheme shown in Fig. 2 is designed to be general enough to integrate within the Ecosystem Service cascade (Fig. 1), like value attribution or exploitation, which can be described in a similar fashion and be integrated into a coherent overall project description (Fig. 12). In Fig. 2, the arrow from the ecosystem to the services does not imply a direct generation, but to illustrate to which of the services the factors and processes analysed contribute. The constitution of the potential and the socio-political process of defining on how to mobilise it have to take place between the steps, i.e. the steps of use value attribution to ESF, and of ESP mobilisation.

\section{LEGATO regions}

The LEGATO work is region-based but in order to derive solutions potentially transferable to other regions, the research is both cross-regional and cross-national with a total of 7 regions and 70 core sites. The regions, landscapes and sites analysed within LEGATO (see Settele et al. 2015; Klotzbücher et al. 2015a, b) are predominantly shaped by human activities and so are the ecosystems they host. Consequently, when analysing ecosystem structures and processes, and their emerging functions, both the ecogenic factors and anthropogenic inputs and impacts (e.g. land management determined by economic, political and cultural factors) have to be integrated.

The topographical similarities allowed the selection of comparable transects of regions in both Vietnam and the Philippines along gradients which reflect different land system archetypes (Václavík et al. 2013) with changing climatic and orographic conditions (characteristics explaining the topographical relief of mountains) and land use intensities, and also different levels of socio-economic and cultural diversities (see Table 1). They range from mountain areas via fertile hilly lowlands to low-laying, flood-prone high production areas. In both countries, the mountain areas are characterised by the terrace agriculture of indigenous peoples. The final study regions were selected along those gradients, with the final positions also reflecting the results of focus group discussions and interviews with stakeholders (i.e. already the choice of sites followed a transdisciplinary approach). In the end, a set of seven regions $(15 \mathrm{~km} \times 15 \mathrm{~km}$ 
Table 1 LEGATO regions along orographic-climatic gradients and their categorisations reflecting a spectrum of land use intensity, structural diversity and cultural diversity. Source: qualitative or semi-quantitative assessments by the LEGATO team

\begin{tabular}{|l|c|c|c|c|c|c|c|c|}
\hline \multirow{2}{*}{$\begin{array}{l}\text { LEGATO region } \\
\text { (name of province) }\end{array}$} & \multicolumn{3}{|c|}{ Land use intensity } & \multicolumn{3}{c|}{$\begin{array}{l}\text { Landscape structural } \\
\text { diversity }\end{array}$} & \multicolumn{2}{c|}{ Cultural diversity } \\
\cline { 2 - 10 } & Low & Medium & High & Low & Medium & High & Low & High \\
\hline Philippines (Luzon island) & & & & & & & & \\
\hline Laguna & & & & & & & & \\
\hline Nueva Ecija & & & & & & & & \\
\hline Ifugao & & & & & & & & \\
\hline Vietnam & & & & & & & & \\
\hline Hai Duong & & & & & & & & \\
\hline Vinh Phuc & & & & & & & & \\
\hline Sapa, Lao Cai & & & & & & & & \\
\hline Tien Giang & & & & & & & & \\
\hline
\end{tabular}

each) was chosen, three in Luzon/Philippines, three in North Vietnam and one in the Mekong delta in South Vietnam.

Classifications of the land use and land cover patterns in all study regions were carried out using SPOT5-satellite images (spatial resolution $2.5 \mathrm{~m} \times 2.5 \mathrm{~m}$, merged panchromatic and multispectral channel). The initial image classifications with Erdas Imagine were subsequently refined with eCognition (in the study regions with more complex landscape patterns PH_3, VN_3, VN_4) and ground-truth data provided by various project collaborators from all study sites (Burkhard et al. 2015). For the study regions' locations and for further details on climates, land uses and soils, see Klotzbücher et al. (2015).

\section{Addressing knowledge gaps: LEGATO research foci}

\section{Ecosystem properties and ecosystem functions (ESF), and the role of biodiversity}

\section{Biodiversity and ESS}

Biodiversity features heavily in discussions of ESF/ESS. However, while most ecosystem functions and services which derive from them probably cannot be produced without elements and/or functions of biological systems, the role of diversity itself (the number of different genetic, taxonomic or functional biological units, as opposed to the material elements constituting it like timber or biomass), plays a limited role in assessment and valuation of ESF/ ESS so far (Meinard and Grill 2011). Harrison et al. (2014) report from their comprehensive review, integrating a multitude of different, both, aquatic and terrestrial, ecosystems and habitats, that the majority of 530 studies testing for an effect of biodiversity on ESS found an increase in service numbers and/or quantities. Nonetheless, they emphasise that for conservation and management recommendations the understanding of the mechanisms behind these relationships needs to be improved. This is partly due to the lack of data across organisational levels from molecular diversity to the diversity of biomes, and to the constraints on resources for systematic monitoring. Lefcheck et al. (2015: 1) identified another obstacle, concluding that the "importance of biodiversity for the integrated functioning of ecosystems remains unclear because most evidence comes from analyses of biodiversity's effect on individual functions" and call for broader research approaches as "the effects of biodiversity on ecosystem function become more important as more functions are considered".

\section{Closing knowledge gaps}

As a consequence, the relation between biodiversity and ESS remains rather underexplored: apart from studies demonstrating the biodiversity-ESS/ESB correlation for a few services, a theoretical construct, a more general explanation of the cause for the correlation is missing: the empirical observations lack proper theoretical foundations. The biological evidence is becoming more solid, although most studies to date analyse the relation of certain elements of ecosystems (and not of their diversity) to ESS/ESB generation, while rarely relating them to sociocultural and social-economic aspects (which makes the definition of services problematic); finally, there are few works empirically demonstrating correlations between biodiversity and ESS at the landscape scale. Some attempts to test whether there is a positive link between diversity and ESS by selectively choosing regions with high biodiversity and comparing them to regions chosen at random did not provide evidence of a significant effect (Naidoo et al. 2008). However, largescale observational and experimental studies have confirmed consistent links between functional group diversity, ecosystem functions and ecosystem services (see, for example, de Vries et al. 2013; Tsiafouli et al. 2015), and recently advanced modelling helped to unravel mechanisms linking productivity and plant species richness (Grace et al. 2016). 
Moreover, the importance of biodiversity for the stability of ecosystems and ESS above and below ground is increasingly recognised (Ives and Carpenter 2007; Wall and Nielsen 2012). Single ESF or ESS are sometimes found not to be dependent on biodiversity, for example the specialisation in agriculture with genetically homogenous seed and high pesticide demand which decreases all levels of biodiversity is a result of management for maximising just one service, yield, at the expense of others. Lefcheck et al. (2015) therefore emphasise that more attention should be paid to the provision of ecosystem multifunctionality which strongly depends on the biological richness of a system. Soliveres et al. (2016) recently reported that high levels of diversity across nine different trophic groups, including 4600 taxa, jointly affected 14 ecosystem functions and services in grasslands and that multitrophic richness was most beneficial for regulating and cultural services and for multifunctionality of the ecosystems.

In arable ecosystems, overall biodiversity depends mostly on soil organism and plant (incl. weed) diversity. High weed diversity is generally acknowledged as fundamental for, and indicative of, high overall diversity, although correlations of diversity patterns across taxa have been found to be weak in some studies (Billeter et al. 2008). In many European countries, agri-environment schemes (the pro-environment measures in agricultural management eligible for EU funding) have been suggested and implemented attempting to conserve the diversity of arable fields and of the cultural landscapes as a whole.

Rice ecosystems and their biodiversity vary in climate, geomorphology and farming practice. In Southeast Asian rice ecosystems, as studied by LEGATO, weeds may provide various services, including ruminant food and feed resources (Kumalasari et al. 2014), but the spatial and temporal differentiation of weed vegetation is as yet little known.

Differences in plant species numbers and composition have been found particularly between lowland and upland areas (Fried et al. 2017), and there is evidence that traditional multiple and intercropping systems should be promoted to support high plant diversity levels in smallholder landscapes (Kumalasari and Bergmeier 2014). LEGATO contributes to a better understanding of the variation in plant composition through a series of study sites in Vietnam and the Philippines, at different altitudes, and with different human impact on fields and surrounding structures. The focus of the research is at field and landscape scale, and the land use intensity has been found to be much reflected by the weed diversity (Fried et al. 2017).

\section{Landscape complexity}

While it has been shown that landscape complexity can enhance the populations of natural enemies and thus benefit crop production by reducing pests (Rusch et al. 2013), the effects of landscape structure in rice agro-ecosystems have been largely unknown. LEGATO combines extensive field sampling of arthropod communities with the analysis of GIS and remote sensing data to examine the relationship between the metrics of landscape composition and configuration and the structure of arthropod community at $300 \mathrm{~m}$ buffers around each study site (Dominik et al. 2017). Landscape complexity, in particular the proportion of rice and non-rice habitat, affects guild composition and species richness of the arthropod community but the responses vary between taxa, especially for the two main pest species the brown planthopper and the white-backed planthopper (Heong and Hardy 2009). A better understanding of the role of landscape complexity in biological control could not only support crop production and efforts to minimise pesticide use (Bengtsson 2015), but can ultimately result in increased economic, social and environmental sustainability of the farming system. In addition, a better protection of non-crop habitats can also enhance a range of cultural services such as the aesthetic value of the landscape, cultural heritage and the opportunities for eco-tourism (Tekken and Settele 2014).

\section{Decomposition and nutrient cycling}

The decomposition of organic material is one of the most important functional processes regulating energy flows and nutrient cycles (Lekha et al. 1989; Dungait et al. 2012; García-Palacios et al. 2013). However, the effects of agricultural intensification on decomposers are still poorly investigated, even though a functional decomposer community is an essential part for the development of sustainable agricultural management practices (Beare et al. 1997; Creamer et al. 2016). The decomposer subsystem is therefore an ideal system demonstrating a strong pathway from anthropogenic management via biodiversity, the functioning of ecosystems to an ESS (soil fertility) and an associated benefit (yield). Moreover, given the strong link between decomposers and biocontrol of pests by predatory invertebrates (Settle et al. 1996a, b; Barrios 2007; Birkhofer et al. 2008; Wurst 2010), considering the effects of management practices on soil biota may help to support a diverse and functioning soil microbial and faunal community (Bengtsson 2015), ensuring soil nutrient cycling (van der Heijden et al. 2008), soil stability (in wet rice agriculture not the most important factor) and providing protection of plants against pathogens (Bardgett 2005; Bardgett and van der Putten 2014).

The link between anthropogenic influences on this relationship is complex and may be affected by processes on different scales. For instance, the regional pool of species contributing to a given ESS might be affected by landscape management and the corresponding quantity and quality of habitat structures (Flohre et al. 2011). This is especially relevant for organisms which switch between an aquatic and a terrestrial phase during their life cycle (e.g. chironomids). 


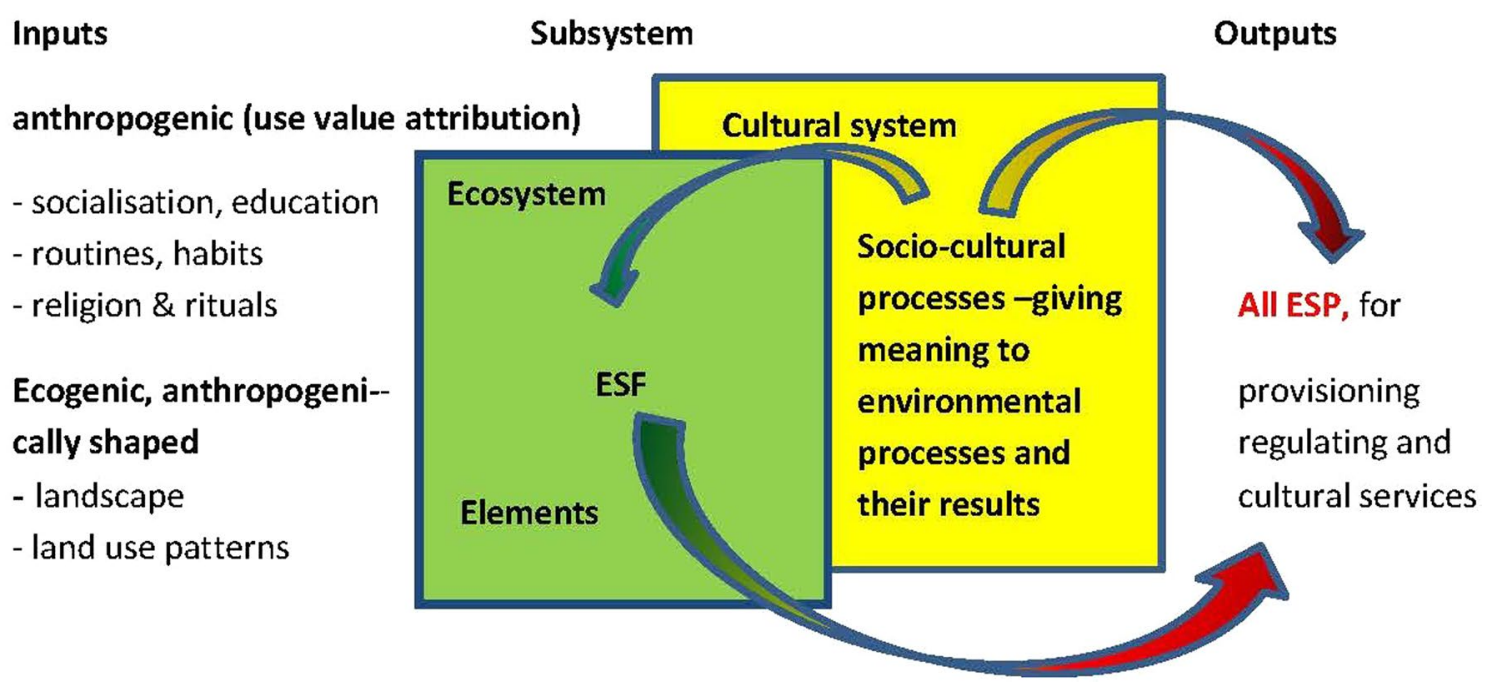

Fig. 3 The sociocultural processes of society attribute certain ESP to recognised or imagined ESF. In the next step, the ESP are mobilised to generate ESS and their ESB

Further, and on a more local scale, different management practices (e.g. crop residue management, application of agrochemicals) affect the diversity and abundance of the aquatic as well as the soil fauna, including their effects on decomposition dynamics (Paoletti and Bressan 1996; Peters et al. 2013; Schmidt et al. 2015b). In LEGATO, we analysed such practices and their impacts on decomposition and invertebrate diversity on this scale with experimental designs allowing us to integrate specific questions into the large framework of the LEGATO studies.

We could show that decomposer invertebrates can completely compensate for the reduced microbial decay rates under the anaerobic soil conditions prevalent in flooded rice fields (Schmidt et al. 2016). Therefore, invertebrates are of particular importance for the effective decomposition of rice straw litter in this environment (Kögel-Knabner et al. 2010; Schmidt et al. 2015a, b). We could also show that landscape structures next to rice fields accelerate the rice straw decomposition by the invertebrate fauna (Schmidt et al. 2015a). Further, using rice straw as organic fertiliser significantly increased invertebrate abundances, especially in the aquatic phase of the fields (Schmidt et al. 2015b). With our experiments on a local scale, we gained important insights in decomposition dynamics as well as abundances and the diversity of a wide variety of invertebrates inhabiting paddy fields with their different functional roles in regulating energy flows and nutrient cycles and therefore soil fertility. These findings may be transferable to different regions of rice cultivation contributing to an improvement of sustainable agricultural practices to stabilise or even increase yields, reduce water consumption and trace gas emissions while preserving biodiversity and natural landscape structures (Václavík et al. 2016)

\section{Sociocultural processes and ecosystem service potentials (ESP)}

ESP are established in a co-production process by human societies defining potential uses of ecosystem structures and functions (Fig. 1); this cultural appropriation of a natural space as a basis for livelihood intersects with the sociocultural evolution of a society. It is this socio-ecological system which has to be analysed to gain understanding of the processes the generation of ESS depends on.

Space is not only a physical property independent of humans, but in its role of perceived, interpreted (let alone physically organised, managed, structured) space; it is a result or product of human activities which in turn determines and structures human activities (Weichhardt 2007); the process is reflexive as spatial contexts influence human activities (Massey 1999). In this sense, a cultural landscape like the rice agriculture landscapes LEGATO focusses on represents a human-appropriated space based on expected or experienced benefits (ESB). The recognition and mobilisation of ESP and the subsequent exploitation of ESS (including natural resources) draw on a valorisation of nature and on a perception of the suitability of a space or landscape to create a livelihood, here called use value attribution. Thus, the physical material world and society form a hybrid metabolic system (Weichhardt 2007) in which next to the material dimension, societal rules and settings play an important role, and by shaping human activities, determine social and spatial settings (Werlen 2000). Thus, the recognition of the potential usefulness of certain ecosystem elements and functions (use value attribution), and the transformation of respective ESPs into ESS (ESP mobilisation) are predominantly sociocultural processes, both restricted and 
empowered by the formal and informal institutions of society (Fig. 3).

Some of these ESP may be independent of each other, while others are mutually dependent, co-produced or building upon each other. According to our definition elaborated earlier, out of many and partly mutually exclusive service potentials, a part is selected by society to be mobilised, and the ESS to be realised. Others are not mobilised due to economic (e.g. because they are unprofitable), social (e.g. uneven distribution of impacts between social groups), cultural (e.g. taboos), legal (e.g. regulations or laws) or power reasons (e.g. competing interests) (see Fig. 3). In order to mobilise the service supply potential attributed to an ESF, and to mitigate potential disservices (Förster et al. 2015), at least for provisioning and cultural ESS, the (conscious) investment of time, labour, physical resources and often money as a means to mobilise them is required to produce ecosystem services in order to gain a benefit, as depicted in Fig. 10.

Recognising a space or a landscape and its use potentials requires an act of abstraction from and an interpretation of the mere biophysical entities, based on a long-term sociocultural evolution, related socialisation-dependent codes and milieus (Kühne 2013; Hokema 2012). This societal construction of a space (or "geographical imagination") (Werlen 2000) implies the central role of individuals who create the linkages between the social and material dimensions of a landscape (Kühne 2013). In the context of the ESS framework as shown in Fig. 1, by the recognition of ESF, value attribution to constitute ESP and the mobilisation of ESS, ESB are generated and allocated (see Fig. 3). The process is complex with an inherent dynamic and influenced by sociocultural development and natural processes.

\section{Ecosystems services (ESS)}

Following the flow of events down the ecosystem service cascade after a societal decision which ESP is attributed to an ecosystem and its functions, the chosen bundle of ESPs has to be mobilised (Fig. 1). Providing the energy, material and human resources (skills, time, labour) to be invested to achieve this is another socio-economic contribution to ESS provision. Money is often, but no way exclusively, a means to mobilise these inputs. Benefits (ESB) gained from nature but not recognised as such are not considered to be the result of ESS; they have no economic value as economic valuation is based on subjective preferences and requires recognition of benefits and their origins (Spangenberg et al. 2014b).

While for provisioning services the recognition of benefits is usually no problem (grain is sown, trees are cut, etc.), and cultural services often require mobilisation by societal/ community processes (e.g. travels, rituals), regulating services are not easily recognised as such. Only few of them, such as pollination, are well known to the beneficiaries and the public at large, as our interviews in LEGATO have shown; for others like biocontrol the knowledge is vague or-for instance regarding climate regulation-almost completely absent amongst the local stakeholders, although the vast majority of them was ranking climate change as one of the two most important threats of the coming decade. However, when in a screening study of ESS in all LEGATO study regions (Burkhard et al. 2015) local stakeholders were asked to identify land cover types' capacities to supply ESS within "their" region (after Burkhard et al. 2012), the results revealed, among others, a high relevance of provisioning and regulating ESS for rice agriculture.

Many regulating services are public goods, i.e. nobody can be excluded for enjoying them and the gains of one beneficiary do not diminish those of another (think of flood protection which serves all people in a region protecting their lives, and-to a varying degree-their assets). For LEGATO this implies that the three kinds of ESS analysed require different communication strategies, adapted to the respective cultural context.

\section{Provisioning ESS}

Provisioning services provide individuals or groups with goods which can be consumed, sold or used for further production. Within LEGATO nutrient cycling was analysed as an ESF generating nutrient provision as a provisioning ESS in its own right, which at the same time is an important component of the food production system and thus closely linked to other provisioning ESS. Water and crops are consumer goods investigated in LEGATO, while nutrients are "invested" in future agricultural production.

\section{Nutrient and water provision}

In agricultural ecosystems, soil plays an important role for the generation of provisioning and regulating ESS (e.g. food provisioning, climate change mitigation) (Fig. 4). To more clearly understand the state and its dynamics, a diversity of factors has to be analysed and their systemic interactions understood. Soil properties such as texture, mineral composition and organic matter content determine the soils ability to store water (water holding capacity), to release nutrients by weathering and to absorb solutes (cation/anion exchange capacity) and to serve as habitat for the microbial community and soil meso- and macro-fauna, which are directly related to the biogeochemical cycling of carbon and other nutrients. According to the classical concept by Jenny (1941), soil properties are determined by a diversity of soil formation factors, including climate, organisms (including human impact), relief, parent material and time. The potential of a soil to provide a certain ESS/ESF will depend on the combination of different properties. For example soils with 


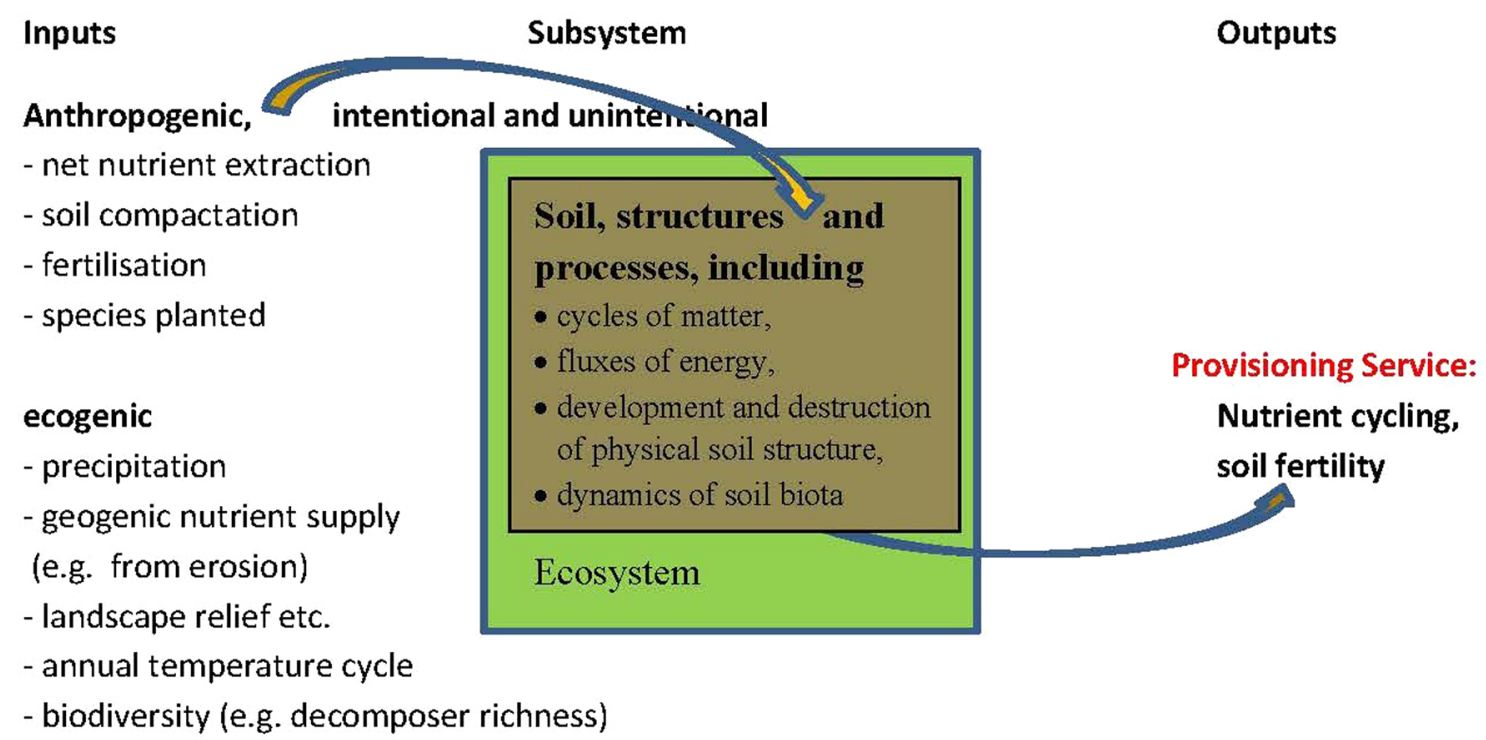

Fig. 4 The soil is a key component of the ecosystem and decisive for its capability to provide provisioning services. Net nutrient extraction and soil compaction by grazing animals are unintentional, planting and fertilisation intentional human interventions

high concentration of mobile $\mathrm{Fe}^{2+}$ under reduced conditions might have a very low potential for food production (Fe toxicity) despite favourable levels of macronutrient supply, texture suitable for the establishment of rice paddies and high content of organic matter. The combination of certain soil properties does not occur at random. Particular combinations of drivers (i.e. soil formation factors) result in particular soil types. Soil types are the taxonomic units used in soil science. Their definition goes beyond the pure description of properties as it includes the genesis of a site and includes some spatial information (sequence of soil horizons with distinct extend and properties).

Some soil properties such as soil organic matter and the content of plant-available nutrients are much more "manageable" than other inherent properties such as temperature, texture and clay mineral composition. Understanding their interactions and the impacts on fertility supporting processes like nutrient provision, water cycling and biological activity and the influence of external drivers, natural (climate, natural hazards) as much as anthropogenic (land use, farming practices), is important for deriving sustainable agriculture concepts (Brady et al. 2015). Such concepts are needed to prevent soil degradation processes like erosion, sealing, compaction, pollution, loss of organic matter and declining biodiversity (Dominati et al. 2014).

In irrigated rice ecosystems, two otherwise unusual soil properties play a key role. Firstly, the practice of "puddling" (tillage of flooded soil) usually leads to the formation of a dense soil layer ("plough pan") which reduces leaching of the flood water to deeper layers of soil. The high water demand is an important characteristic of irrigated rice production systems, and unless water is abundant, any watersaving factors are of great economic and ecological importance. The soil assessments within LEGATO showed that at some sites in the mountains, plough pans are hardly developed, which makes a permanent water supply throughout the growth season indispensable. Secondly, rice-like other grasses - contains an unusually high concentration of silicon (Si), indeed more than most other plants. Recent research suggests that a sufficient $\mathrm{Si}$ availability is beneficial for rice growth (Guntzer et al. 2009). The factors controlling Si cycling and availability in rice soils are, still, understudied. Within the LEGATO project, it was shown that plantavailable $\mathrm{Si}$ is low in Vietnamese, and high in Philippine paddy soils. This finding can be explained by differences in geologic and pedogenic conditions between the countries (Klotzbücher et al. 2015a, 2016). In Vietnam, the low Si availability might limit rice production. However, farmers might be able to increase Si supply to rice by fertilising $\mathrm{Si}$ and recycling Si-rich rice straw (Marxen et al. 2016). Also changes in water management may affect $\mathrm{Si}$ availability (Klotzbücher et al. 2015b).

Soil and plant analyses together with the experiments analysing the role of microbes and invertebrates in rice straw decomposition (described in the "Ecosystem properties and ecosystem functions (ESF), and the role of biodiversity" section) contribute to clarifying the functioning of this compartment. Understanding this module of the overall system is indispensable for getting to grasp with the rice production system as a whole, as it is with any other agricultural system. 
Inputs

anthropogenic

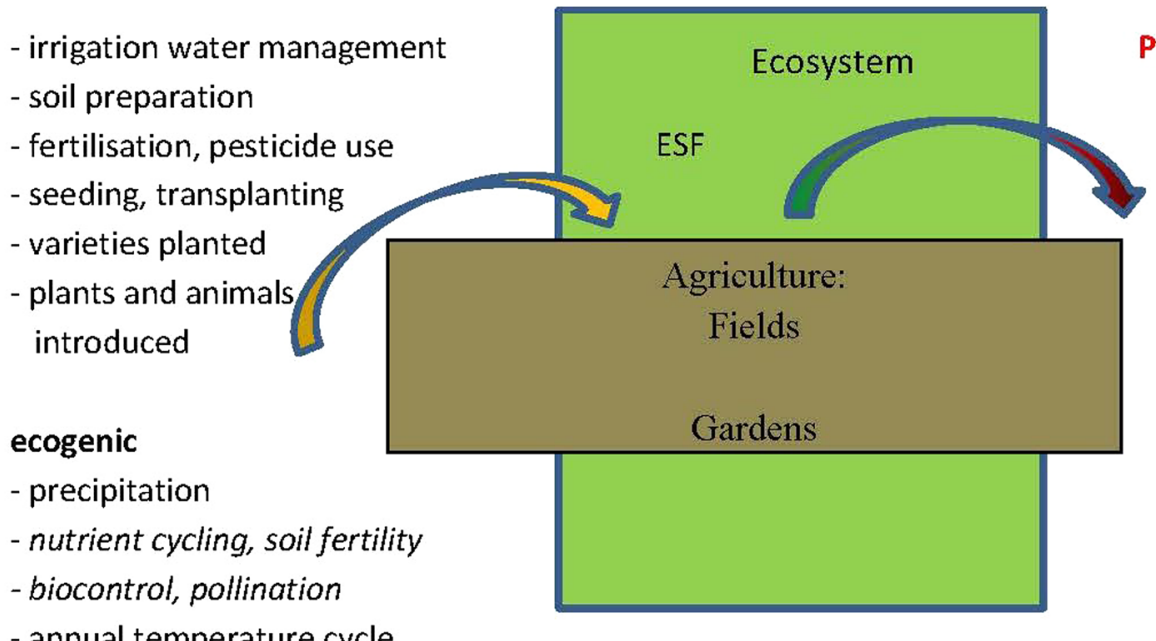

Outputs

Provisioning Services:

\section{Rice grown}

fish, molluscs, ducks,

chicken in the

paddy fields

Fruit, vegetables, ornamental and other plants

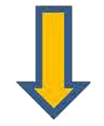

ESB
Fig. 5 Agriculture is an ecosystem-based anthropogenic activity. Multiple human interventions have to be analysed, including their interaction with ecogenic factors. The effects found regarding nutrient cycling and soil fertility, biocontrol and pollination have to be integrated into the analysis. The ESS are turned into benefits in differ-

\section{Crop production}

One key provisioning ESS in agricultural landscapes is crop production, in LEGATO the production of rice. Insights from soil fertility and nutrient cycling, biocontrol and pollination analysis (see next section) are used in the further analysis (Fig. 5).

For this purpose, not only natural science analyses of biomass growth on individual fields provide important information, but also interviews with farmers, a contribution from social science. The farmers provide information regarding the inputs they use (seed, fertiliser, pesticides, machinery, work, water) and the outputs they appropriate (mainly rice, some intermediate or by-products from the fields, plus fruit and vegetables mainly from the gardens, and cultural ecosystem services). Combining the analysis of cultural conditions, contributions and constraints with an economic analysis helps to understand the prevailing land management system and to assess the opportunities for improving livelihoods. Natural science analyses help to understand the effectiveness of the measures reported by the farmers and can serve for their validation.

Regarding the ecosystem service benefits (ESBs), their definition and realisation (appropriation and commercialisation) always depend on the local situation including ent ways, according to the prevailing local culture. Plants and animals introduced refers to animals like fish and molluscs-e.g. non-native mussels in Banaue, snails transferred from lower terraces to higher terraces in Sapa-which are added to rice fields by farmers, to be reared there and harvested later

tradition, culture and habits. This is also obvious within LEGATO, where the situation differs substantially between research regions. In the mountain regions in both Vietnam and the Philippines, subsistence economy structures dominate, while in South Vietnam and parts of the Philippines the production is fully commercial, market integrated (Pingali et al. 1997; David and Ostuka 1994). Other regions (the lowlands of Northern Vietnam with an average farm size $<1$ ha) show a mixture-farmers plant an "aromatic" but lower yielding variety for personal and family consumption (use value generation), while growing high yielding varieties for the market on the rest of his/her land (exchange value generation: monetary income). Market production in Southern Vietnam and much of the Philippines draws on larger fields and knows no such set-aside land used to produce for family consumption.

\section{Regulating ESS}

Regulating ESS are services which do not directly provide benefits, but do so by influencing biogeochemical processes. For instance, water retention in the soil can reduce erosion and flooding, coastal mangrove forests can reduce the impacts of floods by, e.g. reducing flood risks to houses 


\section{Inputs}

anthropogenic

- insecticide spraying

- managed landscape diversity

- fertilisation

- species planted/monocultures

- synchrony/ratooning

\section{ecogenic}

- species and food webs

- growth rates

- mutualism

- population densities
Subsystem Outputs

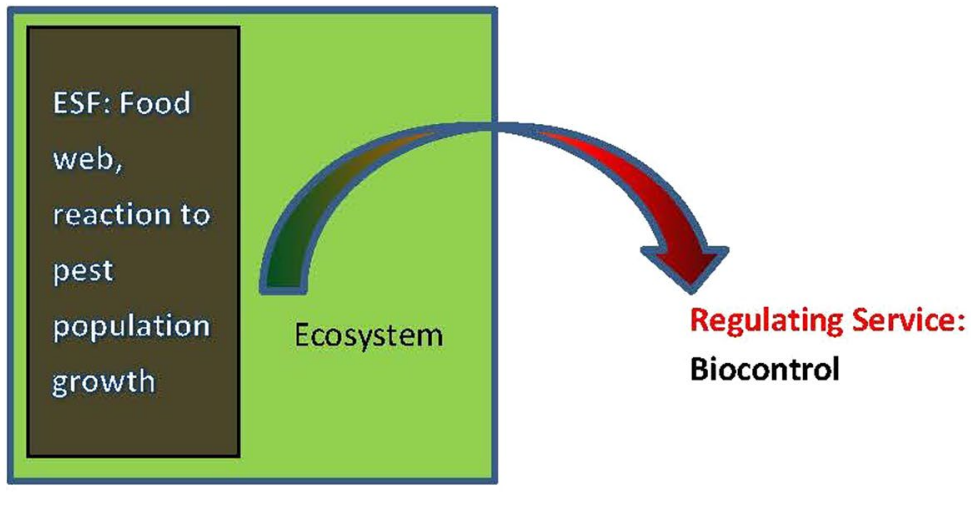

Fig. 6 Biocontrol as ESS based on ESF such as food webs or population growth rates. The effectiveness of biocontrol can be enhanced or diminished by anthropogenic interference

near the water front, carbon fixation can mitigate climate change and the vegetation influence on the microclimate can moderate macro-climate developments. Many of the regulating services benefit humans through the provisioning services they make possible, like pollination leading to (higher) yields to be harvested. In LEGATO, we analyse two core regulating services, natural biological control of rice pests (hereafter pest control or biocontrol, Fig. 6), and crop pollination (Fig. 8). Crop-related biocontrol and the species contributing to them are analysed in the rice paddies, while pollination is predominantly located in the surrounding vegetation, incl. gardens (Samnegård et al. 2011; Hass et al. in prep.) and those fields planted with fruit trees and vegetables. These analyses also contribute to clarifying the relation of ecosystem services and biodiversity in agricultural landscapes. An important step here is analysing the species diversity in guilds within the rice paddies and in their immediate vicinity.

Good examples for these interactions are dragonflies: their aquatic larvae predate on mosquitoes and invasive snails in the water bodies of the paddies and the adults on pests, like leaf- and planthoppers (Ott 2015). Their general diversity in the paddies and their surroundings is influenced by the habitat heterogeneity of this area. As a consequence, their diversity could be used as an easy and quick indicator of the landscape quality.

\section{Biocontrol/pest control}

As agricultural systems are early succession stages permanently set back to the same dynamic and productive starting phase by human steering and intervention; they are not stable states but can be in a state close to system discontinuities. Far from equilibrium (left alone they would disappear through succession) they can be described as dissipative structures in need of a continuously high throughput of resources (energy and materials) to maintain their structure (Prigogine and Stengers 1984). The limited resilience resulting from suppressing natural regulation processes renders further intensification (i.e. increasing input levels) risky; it may push many systems over the threshold of system stability, not least by negatively influencing biodiversity (Hautier et al. 2015). In those cases not only the provisioning services like harvest and soil fertility would be at risk, but also essential regulating services which are the base of drinking water quality, food security and human health, in particular in Vietnam (Hoai et al. 2011). Instead management strategies should move the system further away from potential tipping points and enhance resilience, in particular by strengthening natural regulation processes such as the biocontrol of herbivores (pests).

Herbivore populations are naturally regulated by a range of interacting natural enemies that respond to herbivore population changes, brought about for instance by climatic and other environmental conditions (Schmidt et al. 2003). In rice ecosystems (like in most other agro-ecosystems), two main functional groups or guilds stand out, predators and parasitoids (Heong et al. 1991). The effectiveness of such natural enemies is influenced not only by natural (if anthropogenically modified) pressure factors, but also by management decisions including the choice of the rice varieties used and farming practices like the kinds and amounts of fertiliser and pesticides applied (Bengtsson 2015). Landscape management decisions like the choice of surrounding crops or the floristic composition of set-aside habitat, including the management of plants on rice bunds influence the functionality of the cropping system in general, and the effectiveness of 
Inputs

anthropogenic

- insecticide spraying

- agriculture, plantations, managed landscape diversity

- honey bee deployment

ecogenic

- abundance and diversity of wild bees and other pollinators

- foraging and nesting habitats

- plant communities' diversity
Subsystem

Outputs

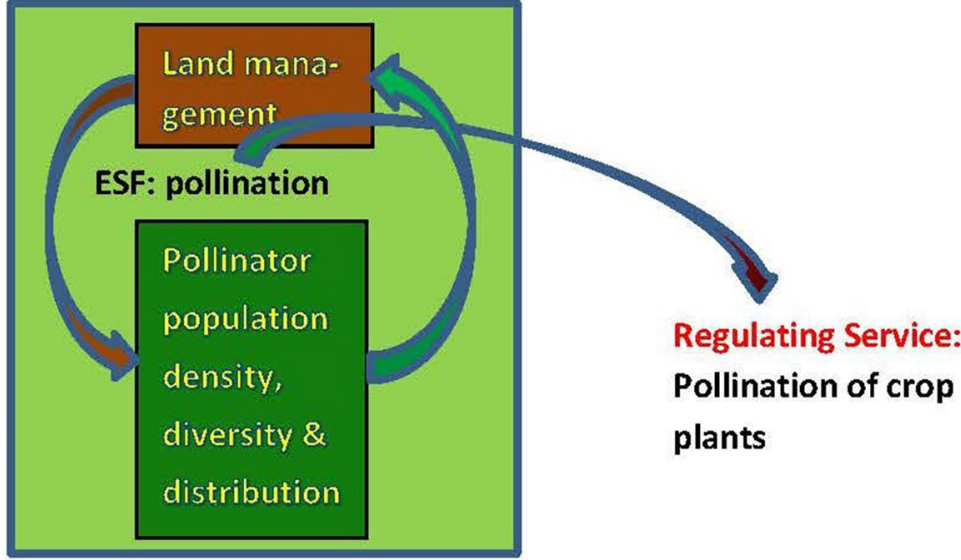

Fig. 7 Effective pollination requires a diversity of pollinating species, often adapted to specific hosts. While an indispensable process for ecosystem functioning in unmanaged ecosystems, humans benefit specifically from pollination of crop plants like fruit and vegetables

the natural pest control in particular (Dominik et al. 2017; Tylianakis et al. 2007). As biodiversity is a decisive factor in this respect (Way and Heong 1994), LEGATO has monitored and inventoried the invertebrate fauna of rice fields and the responses of some of these, particularly egg parasitoids, to variations of herbivore populations. Thus, LEGATO has analysed the predator and parasitoid components as the first step, but also compiled the names of rice varieties used in the fields, documented management practices (Sattler et al., this issue) and defined surrounding habitats as factors influencing biocontrol effectiveness (Rusch et al. 2013; Tscharntke et al. 2007). One recommendation derived from these analyses is, for instance, the proposal to maintain throughout the year small natural water bodies in the vicinity of the fields for a faster recolonisation of the paddies by dragonflies as beneficial insects.

Beyond insects, other pesticides such as molluscicides can also have severe impacts on non-target organism, as many insecticides or molluscicides are not specific to certain pests. For instance, golden apple snail (Pomacea spp.), a widespread invasive pest in rice, is mainly controlled by synthetic molluscicides by farmers, due to their effectivity and despite of the awareness of farmers for the impairment of the environment and their own health by these chemicals. This kind of pest snail management and presumably to some extent the snails themselves have led to a strong decline in native molluscs in rice fields (Horgan et al. 2014). Native molluscs, however, serve as food for predacious species and humans and might contribute to the ESS of nutrient cycling by their activity as decomposers.

Socio-economic synergies emerge not only through the reduction of costly inputs, but also through the additional introduced by anthropogenic land management. It includes inputs beneficial to pollinator populations as well as those detrimental like insecticide use

production opportunities emerging from ecological engineering (Westphal et al. 2015), in particular from planting vegetables in addition to rice, increases in honey production, and from having more time for raising livestock (e.g. ducks or chicken). Obviously, for biocontrol analysis as for all agricultural management activities, ecogenic and anthropogenic factors, both potentially positive and negative, have to be taken into account.

\section{Pollination}

In order to quantify biodiversity and determine its relevance for the functionality of the rice ecosystem landscapes, LEGATO analyses biodiversity in the agri-environment. The scale of research reaches from the diversity of the crop planted to the larger-scale biodiversity in the surrounding landscape. It includes anthropogenically shaped diversity such as diversity from crop rotations and extensively or non-managed habitats. The impact of habitat and landscape heterogeneity is analysed by investigating richly and poorly structured rice fields and landscapes (see Klotzbücher et al. 2015), as they are known to be associated with higher or lower biodiversity, respectively, in terms of species numbers and habitats (Fig. 7). In this context, the diversity of butterflies and dragonflies in the vicinity of the LEGATO study sites has been analysed in the Philippines as butterflies are sensitive and cost-effective indicators for the biodiversity of terrestrial landscapes (Schulze et al. 2004; Koh 2007; Kessler et al. 2011; Gerlach et al. 2013; Rusch et al. 2013) as dragonflies are for aquatic biotopes. As habitats provide opportunities for foraging and nesting, we consider them crucial for pollination in particular in otherwise poorly structured landscapes. However, enhancing the complexity 
of already richly structured landscapes does not necessarily enhance biocontrol effectiveness any further (Tscharntke et al. 2012); it might even instead result in counter-intuitive negative effects on biocontrol organisms due to intraguild predation, i.e. one natural enemy preying on the other (Settle et al. 1996a, b). In this respect there is a clear difference between pollinators and biocontrol organisms: since they use different resources, natural enemies can thrive in relatively poorly structured crop production landscapes, while pollinators are generally dependent on richly structured landscape elements for foraging and reproduction (Westphal et al. 2015).

Despite the fact that rice is actually wind-pollinated (but see Pu et al. 2014), organism-based pollination is crucial for insect pollinated crops and wild and ornamental plant species, which are often grown close to the fields in adjacent villages (Kremen et al. 2002; Garibaldi et al. 2014). For a balanced and sufficient nutrition in areas specialised on rice production, such additional plants are an indispensable part of the menu. Also honey and other products (including wax, propolis and larvae) from mainly native wild bee colonies are welcome, and a bee hive in the backyard of a farm, although not frequent, is not unusual. Limiting insecticide spraying in rice fields supports pollination in neighbouring non-rice areas (gardens, fruit tree plantations) and thus the nutritional situation of smallholder farmers (Brittain and Potts 2012).

In LEGATO, a diversity of experiments has been conducted to analyse the frequency of wild bees, bumble bees, honey bees and other pollinators, and their dependence on landscape management. Particular emphasis has been given to the question how the known positive effect of ecological engineering on pollination (and biocontrol) can be maximised. To assess the current health status of bee communities, the interactions (in particular competition and pathogens transmission) between non-native and native bee species have been evaluated.

\section{Broad-scale effects of climate and land use change}

Investigation of the interactions between broad-scale climate and land use change and their combined effects on current and future ESS provision in the region was undertaken in LEGATO in order to complement the picture of factors influencing the kind and volume of ESS and ESB generated, by accounting for drivers that operate at larger spatial scales. This required scenarios of potential future climate and land use conditions in all seven study areas. The climate scenarios, provided by five general circulation models (GCMs) applying three SRES emission scenarios (A1B, A2, B1; climate scenarios developed for the IPCC, see Nakićenović et al. 2000), have been downscaled to match the 30-m resolution of the analysis. The land use scenarios, covering the years until 2030, were built upon experts' knowledge (including questionnaires and interviews with both scientists and local stakeholders) and the DART model of the world economy (Calzadilla et al. 2014; Delzeit et al. 2017). The land use scenarios focused on changes in the area covered by settlements, rice fields, gardens, pasture/grassland and natural vegetation, based on observations by the SPOT satellite.

In order to simulate potential changes in the provisioning ESS of crop production, and in regulating ESS such as water balance and carbon sequestration of natural vegetation, the vegetation and hydrology model LPJmL (Sitch et al. 2003; Gerten et al. 2004; Bondeau et al. 2007; Rost et al. 2008) was applied to quantify the bundles of and trade-offs between competing ESS under these different scenarios until the end of the twenty-first century (Langerwisch et al. 2017). Our projections indicate that under the current land use pattern climate change will lead to a decrease in rice yields as well as fruit and vegetable production towards the end of the century. However, changes in land management strategies have the potential to offset the negative effects of climate change on rice production in the LEGATO landscapes (not necessarily on the national scale) either by increasing the extent of crop area (although mostly at the expense of forest habitats, with corresponding environmental downsides) or by applying optimal amounts of fertiliser, preferably organic fertiliser such as rice straw and manure, to allow for sustainable rice production. Water provisioning for irrigated rice fields is likely to be increased, additionally climate change might shift the months of high water availability. In the natural vegetation, climate change induces a decrease in net primary production and an increase in heterotrophic respiration for most of the study areas, leading to lower carbon sequestration in the region. Under severe climate change conditions (SRES-A2), forest composition in mountainous areas will shift from the dominance of temperate trees to a more heterogenic structure including tropical trees. Under moderate climate change (SRES-A1B), forest composition is likely to maintain the structure required for pest control in rice fields and for preserving the quality of freshwater habitats for fish, an additional food source for local communities (Langerwisch et al. 2017).

\section{Cultural ESS}

A socio-ecological system, the connection between humans and nature is not based exclusively on tangible goods, but comprises immaterial values as well (Fig. 8). In the ESS literature, cultural services have been described as "immaterial aspects of valuation" (Pröpper and Haupts 2014), contributing to human well-being in terms of intangible benefits (De Groot et al. 2012; MA 2005). However, provisioning services can have immaterial benefits (like feeling stuffed with food), and culture is a much richer field than "aspects of valuation" indicates. In the LEGATO project, to assess 


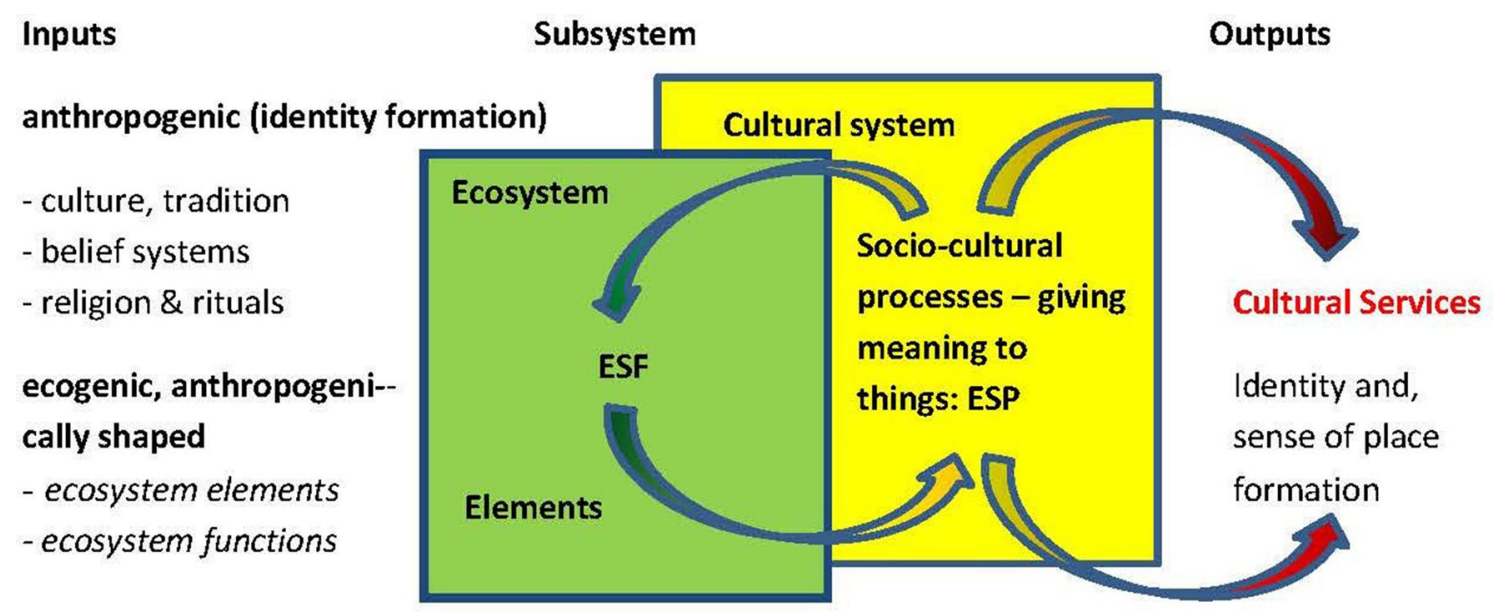

Fig. 8 The sociocultural processes of society and the ecosystem coproduce cultural ESS. Cultural services like identity and sense of place have a strong connotation to the environment, but are shaped by

opportunities for sustainable land management by strengthening functional habitat diversity, three cultural services have been analysed, based on a broad understanding of culture and cultural processes: (1) cultural identity, (2) landscape aesthetics and (3) knowledge systems. The selection of these categories is based on the transdisciplinary integration of the project's initial research question with the input of regional stakeholders from Asia (by expert elicitation, see Görg et al. 2014; Spangenberg et al. 2015b). The categories chosen subsume aspects that are of regional relevance and acknowledge the farmers' internal perception of cultural values associated with and cultural benefits gained from their landscapes, in particular in subsistence and small-scale rice farming (0.5-2 ha), but also in large production sites catering for the global market (Tekken et al. 2017). "Outsider" views, e.g. perceived landscape aesthetic by tourists, were not taken into account. A qualitative approach (narrative, individual and group interviews) to assess cultural services associated with rice landscapes was chosen because intangible benefits are perceived and valued in a subjective manner (Fagerholm et al. 2012). The results give insights into (a) attributed immaterial values, (b) the role of cultural values for sustainable land management, and (c) the indirect effects of agricultural and socio-cultural habits on the functionality of ESS in rice cultivation.

\section{Attributed immaterial values of rice landscapes: cultural ser-} vices and their role for sustainable land management The landscapes assessed are more than functional production sites, they are parts of livelihoods and in this respect social constructs. Community plays a major role. In many interviews farmers emphasised sociocultural aspects as main motivation to accept difficult living conditions, e.g. social structures, cultural traditions, social norms and values and sociocultural processes which give a meaning to the elements of the environment and the ecosystem functions

a "feeling of home" (sense of place), or institutionalised mutual help systems during the rice cultivation stages. Confidence in sufficient production capacity based on local expert knowledge, prospective thinking and the wish for social stability and security for the next generation, and as well the interest in the production of "clean food" support openness for the safer production techniques associated with ecological engineering. In areas where the use of pesticides and mineral fertilisers has been replacing traditional pest control and organic fertilisers, important knowledge inventories are being lost to present and succeeding generations. This applies in particular the cultivation of traditional crops, leading to a substantial change of traditional agro-biodiversity. However, the use of high yielding varieties (HYVs) has substantially contributed to food security and the reduction of hunger in all regions. The question rises, if the replacement of traditional varieties is necessary to ensure food security, at the expense of reduced agro-biodiversity and disturbances in the rice field food web, or if a management system is biologically, technically and culturally possible, preserving a fully functional, adapted agro-biodiversity.

Cultural identity The strong link between nature and man in rice cultivation, inter alia the handling of risks, the development of adaptation strategies, the division of labour and tasks in field work, food processing and trade, has emerged in the evolution of sociocultural milieus, cultural traditions, social norms and values with many common elements, but also with regional differences (Tekken et al. 2017). Identity includes social interaction and the physical material environment. Thus, human activities are an essential part of the processes and structures that produce those cultural services and benefits farmers associate with their rice landscape: identity values (e.g. language, apparel, farmers milieu), 
heritage values (history and tradition, e.g. folk songs and ancient customs), and educational values (e.g. cultural roles and attitudes). As farm workers and managers cultivating other people's land often feel less bound to that heritage, a history of working on one's own land seems to strengthen the link to local or regional culture and identity (Tekken et al. 2017) as does the increasing relevance of ethno- and eco-tourism, enhancing farmers' awareness of the value of their heritage as a source of income, in particular in the financially poor but culturally rich mountain areas.

Landscape aesthetics Landscapes connect nature and culture. However, the respective sociocultural context determines what is selected or perceived as aesthetic landscape elements, not individual processes (Backhaus 2011; Coeterier 1996). For example, in central Europe, the productive use of agricultural landscapes has been perceived as aesthetically appealing, up to a certain point when the changes brought about by intensive production systems began to undermine landscape aesthetics (Wöbse 2002). In the LEGATO sites, the way rice farmers describe their landscapes often equates production values and other forms of usefulness with landscape elements (e.g. rice field or terrace, street) having aesthetic value. Despite an often difficult living situation in most cases a strong and positive emotional attachment to the rural landscape and its familiar structures could be found, even for a better income they would not give up farming (although they often recommend their children to do so). Landscape aesthetics as service category includes characteristic functional landscape elements associated with cultivation (e.g. farmhouses and gardens, stonewalls or rice terraces), characteristic sociocultural landscape elements (e.g. spiritual areas such as cemeteries or shrines close to or in the fields, traditional village structures) and intangible landscape values (e.g. aesthetic emotional contemplation of rice field; bequest and spiritual values, like mountain and bamboo forests, endemic flora and fauna, migratory birds as symbols of "good luck" (Tekken et al. 2017).

Knowledge systems Related to the agricultural specification, production patterns, farming methods, and along with socio-economic and sociocultural developments, different forms of knowledge have evolved and are associated with rice production and sociocultural characteristics: scientific knowledge, intellectual and artistic inspiration, collective expert knowledge and implicit or tacit knowledge (Tekken et al. 2017).

The forming of nature into a human living space is a complex and dynamic interplay comprising a multitude of ESP identification and ESS mobilisation processes. Learning processes in connection with food production are reflected in practical and specialist knowledge (expert knowledge) in the field of agriculture. In the case of the LEGATO landscapes this agricultural expertise, as a cultural service, includes food production on marginal soils, knowledge on climatic conditions, local flora and fauna (beneficial and pest species; rice fish system), handling of risks, problem solving, knowledge and use of local food diversity, adequacy of crops for local soil and climate, production steps (rice cycle), natural medicine and much more. However, this knowledge is not evenly distributed but differentiated by region and social group-traditional priests (mumbaki) in the Philippine mountains pass their knowledge on to their sons, not to the public, and farm workers are often less informed than farm managers.

Indirect effects of agricultural and sociocultural habits on the functionality of ESS in rice cultivation The indirect effects comprise the linkages between landscape, settlements, traditional architecture, cultural practices and traditional land use practices on the one hand, and agrobiodiversity on the other. Besides aesthetics, they include knowledge systems and cultural identity.

\section{Linkages between landscape, settlements, traditional archi-} tecture and agro-biodiversity (Landscape Aesthetics) The structural diversity of landscape patterns is connected with habitat diversity and the occurrence of species (Syrbe and Michel 2013). A richly structured landscape matrix meets the habitat requirements of a wider range of species and provides more ecological resources (Walz and Syrbe 2013; Syrbe and Michel 2013). Also settlement structures can affect agro-biodiversity: traditional villages surrounded by rice paddy fields, private gardens, fish ponds, livestock keeping, irrigation systems, agroforestry, etc., create a specialised biodiversity. Part of this can also be the traditional architecture (e.g. houses and hedges); if, for example, a house is constructed with natural materials (straw, grass, wood, and bamboo), it has the potential to provide man-made habitats for wildlife (e.g. bee hives). The replacement of natural with more comfortable, durable construction material (cement, concrete, or iron/tin roofs) can reduce habitat opportunities. The increasing amount of land used for settlements, transport or other infrastructures affects landscape functions, e.g. it can lead to habitat fragmentation or interrupt wildlife corridors. However, the hypothesis that in those LEGATO landscapes with still high structural diversity of landscapes (mostly mountainous subsistence farming in Ifugao/Philippines and Sapa/Vietnam) farmers are less often affected by the impacts of rice pests could not be empirically confirmed, at least not based on the qualitative interviews. The expected higher species abundance in regions with slow agricultural modernisation processes and often traditional settlement 
patterns did not lead to unambiguously less perceived risk than what farmers in regions with low structural landscape diversity and intensive rice production described. In the latter, insect pests are perceived as a constant threat (e.g. Nueva Ecija/Philippines, Tien Giang/Vietnam).

\section{Linkages between traditional land use practices and agro-bio- diversity (Knowledge Systems) Due to the very limited exter-} nal inputs available, traditional subsistence farming has to take advantage of all available natural nutrient cycling mechanisms, in particular at marginal locations. Rice production traditionally was an integrated system, with other species or crops grown concurrently or with intermediate cropping, e.g. rice fish farming. To achieve optimal results, resources were used as efficiently as possible and created specialist knowledge, e.g. efficient livestock management, water management of paddies, production of organic fertiliser and nutrient management, erosion control, or synchronisation of farming activities for risk distribution. This has produced sensible interrelations between nature and human activities, particularly in areas with poor soils. Meanwhile, in all LEGATO landscapes except the in the Philippine mountains, farmers have exchanged traditional crops with HYVs, apply pesticides, and use mineral fertilisers, at least as an addition to manufactured organic fertiliser. Many (older) farmers stated that with the loss of traditional farming systems-due to several reasons-also species diversity has changed, in and around the fields. However, many interviewed farmers did not actually have deeper agro-ecological knowledge on rice field food webs and the functional relationships of pest and beneficial species. Even if at least fragments of such specialist knowledge were preserved by older generations, it has been fallen into oblivion under the influence of modern production practices.

Traditional cultural practices linked to agro-biodiversity (Cultural Identity) In all LEGATO landscapes, festivals and to some degree rituals are traditional components of the rice cultivation cycle. Until today, they have a social bonding force and are important social events. Parts of these festivals are also regional culinary specialties, in particular sticky rice made from traditional rice varieties (e.g. heirloom varieties in the Philippines). Some of the interviewed farmers in Vietnam provide areas for the cultivation of old varieties, either for the purpose of celebrations or worshipping events, or as monetary reserve for times of short budgets, as the market price is higher than that of HYVs. Farmers who stated that they reserve areas for the cultivation of these traditional varieties also mentioned the excellent adaptation ability of these crops to the marginal conditions. However, the production volumes are low compared to the harvest results of new varieties. The increasing awareness of these cultivars as cultural heritage (e.g. in the Philippines: Manila Bulletin, May 14,
2015, see http://www.mb.com.ph/rare-rice-art-honored-asnational-treasures/) increases the opportunity to save old and regional varieties from extinction, and with this to preserve centuries-old expertise. A further aspect is the conservation of specific agro-biodiversity in areas where these old crops are still cultivated. Most farmers who grow old varieties stated that compared to their conventional fields they do not apply pesticides, but invest more time for the manual pest control and field maintenance (e.g. hand weeding instead of using herbicides, picking of invasive snails instead of using molluscicides). However, this might as well correlate with the financial situation of farmers, in order to save expenses needed for conventional rice production. Essential parameters for the cultivation of old varieties are the age and income situation of farmers: older farmers are able to refer to inherited knowledge and long-term experiences with requirements of the old crops, younger farmers with families must take advantage of every space available to grow rice to ensure food security. Increasing livelihood pressures and economic constraints thus inevitably lead to the reduction of areas and share of traditional rice varieties, and with this of traditional agro-biodiversity.

\section{From ecosystem services ESS to ecosystem service benefits ESB}

Commodification and urbanisation erode indigenous knowledge about sustainable, low input agriculture, which is potentially valuable for sustainable agriculture in both the mountain areas and the lowland (Spangenberg et al. 2014a). The resulting target conflicts of development policy is one of the main reason why unforeseen environment conflicts might arise in Vietnam; recognising increasing ESB from ecological engineering as a valuable contribution to sustainable development is considered to support a shift of the development paradigm towards government support for a policy reducing the negative impacts to environment and ecological systems in rice cultivation areas.

LEGATO analyses the pathways for preserving knowledge and cultures pursued by the Philippine and Vietnamese governments, which are different not least due to the different political systems in both countries. In both Banaue and Sapa stakeholders hope that sustainable agriculture plus ecotourism branding will offer opportunities to create additional income and sustain living cultures. This is the reason why LEGATO has become engaged in eco-tourism development in both Vietnam and the Philippines.

\section{ESBS in LEGATO}

ESS are not yet benefits-in the case of LEGATO, imagine a field full of rice. It represents a provisioning ESS, generated from ecosystem functions (ESF) such as nutrient cycling and water availability. First an ecosystem service potential 


\section{Inputs Subsystem Outputs}

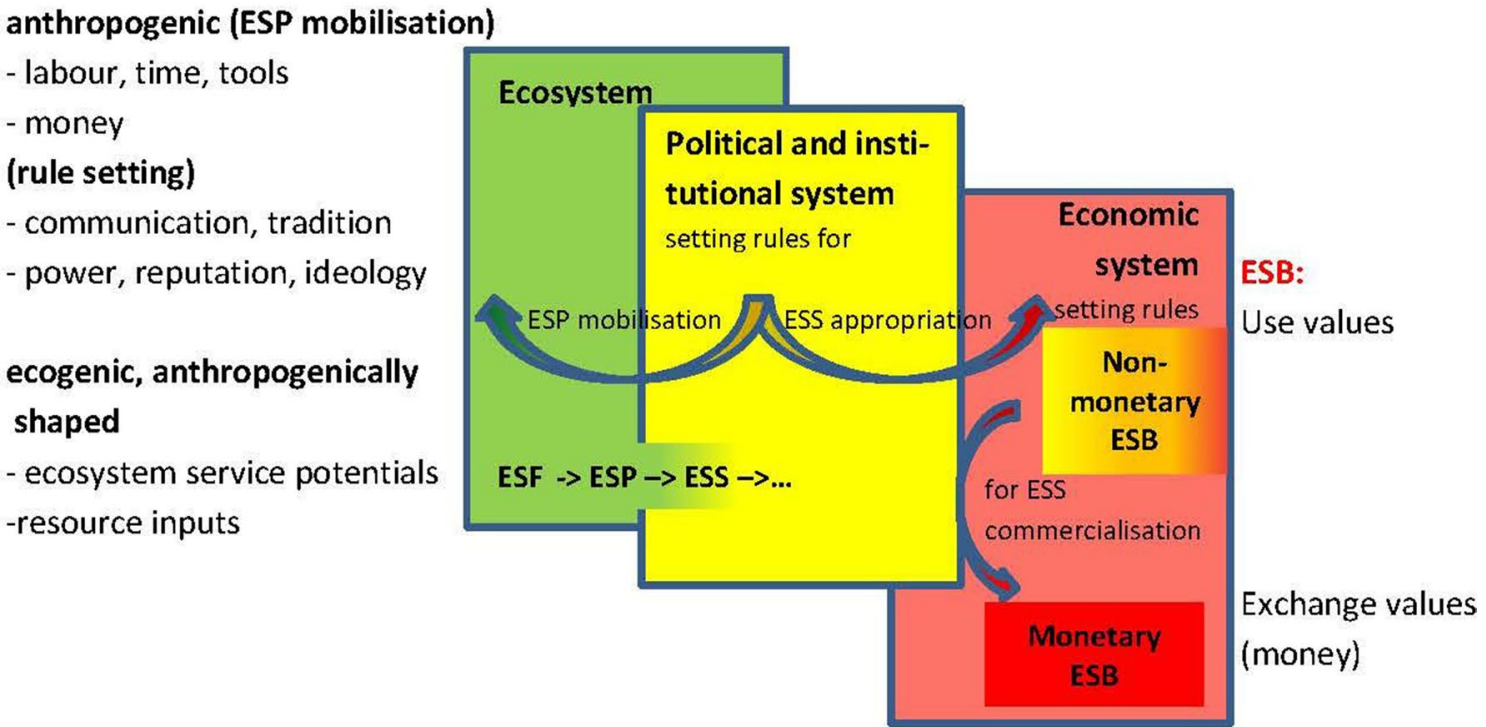

Fig. 9 Political and societal institutions (organisations, mechanisms and orientations for societal decision finding) rule ESP mobilisation and ESS appropriation. The rules of the economic system govern the process of ESB use, be it informal/non-monetary or through commercialisation

(ESP) for rice paddy construction and use must be identified, and effort invested in mobilising it (field preparation, sowing and transplanting). To activate the ESS flow and to reap the benefits by appropriating the ESS, the rice must be harvested, dried, threshed, purified, milled, polished and further processed. Then benefits (food or income) accruealbeit to different degrees-not only to the farmer but to all who are involved in these processes, either commercially or based on mutual support and social obligations.

Any comprehensive analysis of the rice production system must thus include not only farmers, but also decision makers (politicians and administrators) setting the formal framework conditions, and the other relevant actors throughout the value chain (Siew et al. 2016). In LEGATO, a stakeholder analysis was conducted and continuously updated throughout the project, beginning in the preparation phase and extended when new stakeholders were identified. It comprises an analysis of their specific roles, the existing dependencies and formal as well as known informal dominance structures, and their respective share in the benefits (financial or other) gained from the rice production ESS (Fig. 9). For this behalf, representatives of most stakeholder groups, plus other agents offering complementary sources of income, like tourism organisers (state and private), were interviewed. The Philippine political system is opaque; although a parliamentary democracy, many decisions are taken based on ethnic, clan and family relations. Vietnam is dominated by the Communist Party; its decisions are decisive for public authorities and shape the business environment, causing a comparable level but different kind of transparency deficits. To a certain degree, stakeholder analysis had to remain a piece of educated guesswork.

Conflicts in the mobilisation (Fig. 9) and the appropriation phases (Fig. 10) also occur in the LEGATO landscapes, although not necessarily openly visible: in Nueva Ecija, Philippines, farm workers interviewed complained about their situation but felt unable to change it given the power of the land owners, and farmers in Vietnam gave similar statements with regard to government power. Other conflicts may not have been revealed to foreign visitors, for local (conflicts between mining and agriculture abound in both countries, but not within the LEGATO landscapes as there are no mining operations), cultural or political reasons. They can be expected to emerge when different, mutually exclusive ESP are claimed by rival groups (legitimised by common practice, legal regulations or sheer power). Such competing potentials claimed by rival groups are one of the limitations making the ESS supply capacity smaller than the hypothetical ESP, and struggle or compromises reduce the amount of ESS finally appropriated by the victorious agent. Similar conflicts can arise over who is entitled to mobilise which ESP, and who has the right to appropriate which ESS. In LEGATO, potential conflict arenas to be observed include the partly complementary, partly competing role of sustained rice agriculture and expanding tourism, sustainable or not.

For research projects this is an important insight as when coming as external agent with a certain reputation and credibility, a project and its staff will immediately become part of existing conflicts, not as a matter 
Inputs

Anthropogenic (ESS appropriation)

- labour, time, resources

- tools, money

- norms, laws, habits

- tradition, routines

- power structures

- legitimacy \& neediness

Ecogenic, anthropogenically shaped

- ecosystem services
Subsystem

Outputs

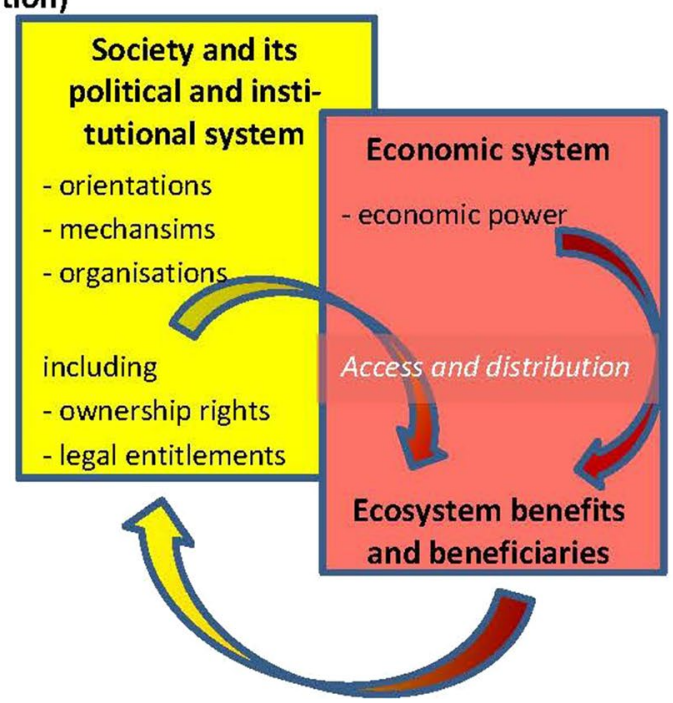

ESB use values, non-monetary value no commercialisation or commodification Social value, but no economic value (price). No supply, so demand is irrelevant.
Fig. 10 Societies' institutions and economic power are decisive for who appropriates which ESS and how, they determine benefits and beneficiaries. The results of this process feed back into society influencing the individual and collective well-being, long before any

of choice but because they and their results are at risk of being instrumentalised by conflicting parties (Falck and Spangenberg 2014; Förster et al. 2015).

\section{Ecological engineering}

The method promoted by LEGATO to generate win-win situations of mobilising ESP with less agricultural inputs while safeguarding or even improving ESB is ecological engineering. It includes measures such as appropriate application of (preferably organic) fertiliser, realising the yield potential of the rice crop but avoiding water pollution and eutrophication by the runoff from the rice fields. Demand for fertiliser can be reduced by avoiding over-fertilisation, by transplanting seedlings early (within 2 weeks) and carefully (single seedlings rather than clumps), with increased distance between seedlings (but also requiring more work). Due to higher tillering rates this does not decrease the harvest but the number of seedlings required, thus saving work and cost (Prasad 2006). Another measure is to refrain from insecticide spraying for at least the first 40 days of the growth cycle (plants recover from damages in this early growth stage). Furthermore, damages can be reduced by the fact that limiting fertiliser application to the physiologically necessary quantum also reduces herbivore population growth rates and can promote effective population regulation or prevent localised herbivore outbreaks through the actions of natural enemies (Huan et al. 2005). Each of these steps saves commercialisation and monetary/wealth effects emerge. As long as nobody puts the service/benefit on the market, there is no supply, and irrespective of demand there is no price

money for the farmer-significant income improvements are possible at the same selling price for rice. Such measures have been widely promoted among farmers in South Vietnam as the Vietnamese government introduced the " 3 reductions, 3 gains" programme as a means to increase the profitability of rice farming, focussing on reducing excessive use of seeds, inorganic fertiliser and insecticides, except for nitrogenous fertiliser use which is to be enhanced (Heong et al. 2010). Through these reductions the programme contributed to improved natural biocontrol of rice pests (Huan et al. 2005; Heong et al. 2010). Some of these steps, plus a changed water management keeping the soil not permanently flooded have been incorporated into what is called the "system of rice intensification" (SRI), developed by farmers and spread by grassroots networks, long ignored by research institutions but currently under scientific analysis (see, for example, Basu and Leeuwis 2012; Noltze et al. 2013; for "ecological intensification"1 more general see Pywell et al. 2015). The case of SRI highlights the importance of farmers' knowledge and is an additional motivation for the participatory approach to a co-production of knowledge pursued by LEGATO.

\footnotetext{
$\overline{1}$ The FAO has defined ecological intensification as a "process that requires optimal management of nature's ecological functions and biodiversity to improve agricultural system performance, efficiency and farmers' livelihoods" (Pywell et al. 2015).
} 
Fig. 11 Ecological engineering is both to restore and conserve biodiversity, ecological functions and ecosystem services. After Heong et al. (2014)

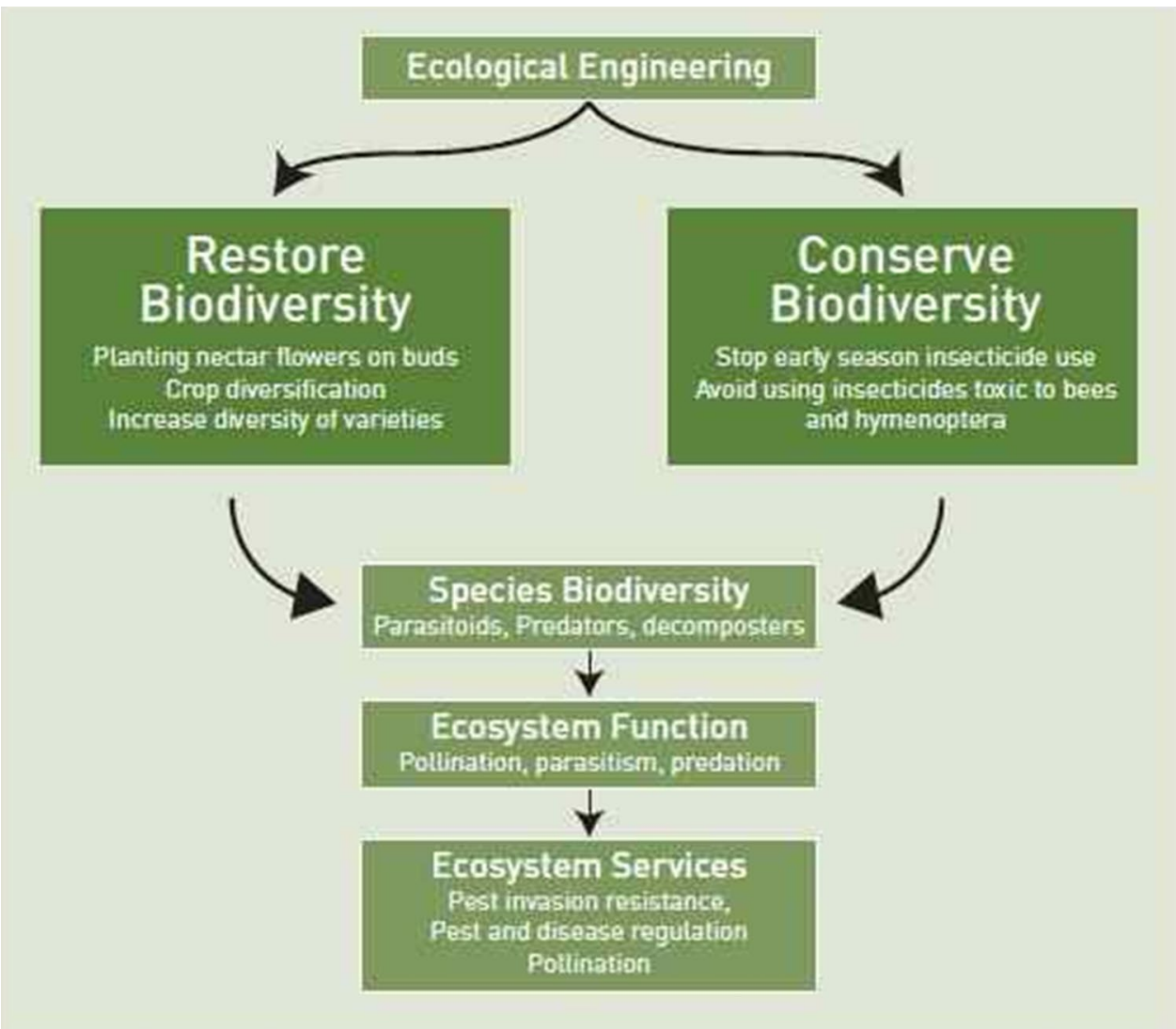

Ecological engineering incorporates a number of such measures, but goes beyond them by emphasising the necessity to substitute insecticide based insect control (and more generally, pesticide based pest control) by biocontrol in rice agriculture. The reasons are multiple: ecological (conserving biodiversity), economic (saving cost) and health reasons (reducing airborne expose and water contamination) mutually reinforce each other. Action is urgent: a significant escalation of insecticide use in rice during the last two decades is very apparent (Islam et al. 2012). The concept involves two main components, increasing floristic biodiversity-also in the water bodies - to provide resources for natural enemies, and reducing insecticide use to conserve biological control agents (Fig. 11). The need for insecticide use in tropical rice is highly debated; several studies have shown that commonly used insecticides can cause the resurgence of rice pests such as the brown planthopper, stem boring caterpillars and even mosquitos (Bottrell and Schoenly 2012; Gurr et al. 2011; Heong et al. 2015). When such insecticides also reduce the numbers or effectiveness of natural enemies, favourable conditions for pest outbreaks are created (Bianchi et al. 2006; Gurr et al. 2011). Non-target species affected to the disbenefits of farmers do not only include directly beneficial ones such as biocontrol or pollination organisms, but also those of indirect usefulness like invertebrate decomposers serving as food for and promoting populations of generalist predators which also prey on pests. Thus, limiting insecticide spraying reduces disruption to the functioning of the biological control ecosystem services and stability (Heong 2009). Increasing floristic biodiversity on the bunds and/or the field margins with plants providing food and shelter for biocontrol organisms, such as spiders, beetles, crickets and parasitoids is essentially easy, but requires changing land management systems and farming practices. However, as biocontrol needs time to unfold, the risk of plant diseases spread by insect borne virus diseases is a challenge requiring specific attention.

Auxiliary management measures can include the synchronising of crop establishment, the provision of resources and refugia for other beneficial species including birds, spiders and predatory wasps, and improved bund management in terms of size and by planting nectar rich plants. Synchronous planting of rice crops has been show to effectively reduce the spread of viruses (such as tungro virus) because the plants and the leafhoppers that transmit the viruses must build up numbers before the rice ages and becomes less suitable as a food source (Norton et al. 2015). Thus, a higher local-scale synchrony of seeding/transplanting reduces the vulnerability, embedded in asynchronous seeding on a higher geographical level, while higher landscape diversity can reduce biocontrol effectiveness (Martin et al. 2013). Planting bunds with plants that benefit natural enemies, particularly during 
early crop stages, can theoretically improve regulation by providing alternative food sources when prey densities are low, or by providing food and refuges for specific life stages of important natural enemies such as parasitic wasps (Lu et al. 2014). An additional measure might be the provision of good living conditions to generalist predators like dragon flies in neighbouring waters. Ratoons (interim rice growth between the main harvests) remain reservoirs of some plant diseases, particularly insect borne virus diseases, like tungro, grassy stunt and ragged stunt (Holt et al. 1996), and also often sustain a small population of hoppers (Chakravarthy 1987) among other insects. This makes the ratoon rice fields a very attractive habitat for predatory arthropods, like spiders and more specialised natural enemies like parasitoids and predatory bugs while it does not promote high hopper populations in the post fallow crop (Schoenly et al. 2010) but might help reducing pest infestation by sustaining natural enemy populations between rice crops. This and the influence of synchrony or asynchrony are analysed in the Philippines by LEGATO research teams.

In a nutshell, ecological engineering offers a way to sustain (non-excessive) agricultural surplus while avoiding contamination and sustaining or restoring natural productivity, not least by enhancing biocontrol. A diversity of natural enemy species will be required for biocontrol to be successful, given the high diversity of potential pest species and need for resilience in the face of changing climate and management practices (Islam et al. 2012; Heong et al. 2013). The most serious obstacle to such behavioural adaptations, despite the economic gains associated with them, are established habits and routines, a mental lock-in with partly devastating results (Heong 2009; Heong et al. 2015; Spangenberg et al. 2015a). Scientists from China, Vietnam, Thailand and the International Rice Research Institute IRRI have begun evaluating the use of ecological engineering as a concept to restore biodiversity and biological control services to sustain pest management (Gurr et al. 2016), including the use of repellent plants to reduce damage by rats, and substitute for the use of rodenticides.

\section{ESS valuation}

Ecosystem services' monetary valuation, and subsequently their optimisation/preservation by being traded on markets, have been promoted for more than 20 years as core means for protecting biodiversity (see, for example, Costanza and Farber 2002; Barkman et al. 2008; Fisher et al. 2009); the approach has found supporters (as well as critics) among economists and natural scientists alike (e.g. Daily 1997; Adams 2014; Tallis et al. 2014). It is argued that monetary values allow going beyond the established perception of biodiversity conservation as nature protection for ethical reasons, which has largely been the justification for conservation efforts, be it in the form of wilderness areas disconnected from the everyday environment (e.g. in the USA) or as extensified areas with use restrictions like the Natura 2000 network in Europe; Asia, while trailing that development, is rapidly catching up, supported, e.g. by the World Bank and its WAVES programme. Furthermore, it is hoped that monetisation can generate new funding for nature conservation, for instance by defining a business case for conservation (Bayon and Jenkins 2010; Daily and Matson 2008; Sukhdev 2009).

However, valuing ecosystem services in monetary terms and trading them on markets has become contested over the last half decade for several reasons: it is argued that monetary valuation cannot measure all kind of services due to methodological limits (Gómez-Baggethun et al. 2010; Norgaard 2010; Spangenberg and Settele 2010; Gómez-Baggethun and Ruiz-Pérez 2011) and has to dissemble individual services from the complex ecological networks sustaining them and of which they are constituted (Rees 1998). Furthermore, doubts have been raised about the approach for ethical and value theory reasons (Spash 2008; Muraca 2011; Potschin and Haines-Young 2011; Haines-Young et al. 2012; Rozzi et al. 2012; Spangenberg and Settele 2016). As far as economic valuation is to provide information about "the difference something makes", e.g. in ex ante impact assessments, marginal value analysis is only possible far from a discontinuity. Close to thresholds or tipping points, the justification of interventions must be political or ethical rather than economic (von Haaren and Albert 2011).

LEGATO partners, working in a transdisciplinary project, are well aware that preserving ecosystem services does not necessarily safeguard biodiversity (Mumby et al. 2008) while vice versa biodiversity loss impinges on productivity and ecosystem service provision as much as major environmental changes like climate change (Hooper et al. 2012). Thus, the economic assessments undertaken do not aim at valuing ecosystems or their functions as such, but are limited to first exploring the values held by stakeholders, and secondly to assess the economic value of the ESB gains and potential losses as manifested in markets. With this limitation we try to avoid the main category errors which have been widely discussed in the ecological economics literature (Spangenberg and Settele 2010), such as confusing the nonexistence of a market price for traditional varies which are not offered on markets with an existing market price of zero, or neglecting the divergence of results if the same object is valued using different methods. In LEGATO we understand ecosystem management as including the improvement of human livelihoods as promoted by the IUCN Commission on Ecosystem Management (IUCN CEM 2006) and the Millennium Ecosystem Assessment (MA 2003). In these concepts the value of nature and biodiversity is a metaphor, not a price. 
Inputs

anthropogenic (ESS commercialisation)

- ESB supply

- ESB demand

- ESB marketing \& advertising

- money \& technology

- customer preferences

ecogenic, anthropogenically shaped

- Ecosystem service benefits
Subsystem

Outputs

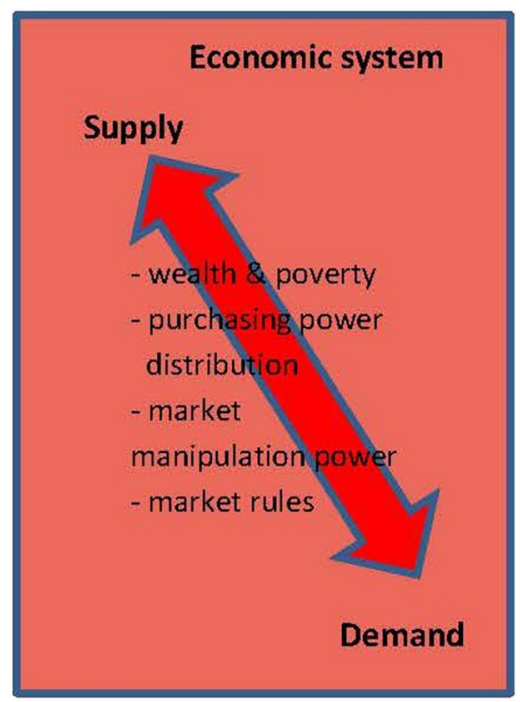

ESB exchange values

monetary value

commercialisation /

commodification,

sold on markets if

demand is sufficient

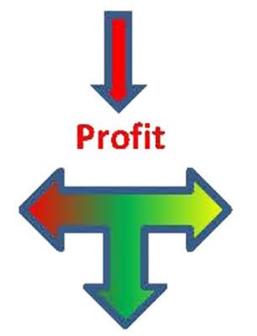

Fig. 12 The commercialisation of ecosystem benefits takes place in the economic system. Depending on demand and supply, and the resulting financial incentives lead to land management adaptations with repercussions for the social/institutional and the environmental system

Consequently, socio-economic valuation within LEGATO (Fig. 12) first of all asks for the subjective importance attributed to a good, the "use value" in classical economic terms (Figs. 1,11) before analysing the process of ESB commercialisation. This does not only refer to cultural ESS and their benefits (like the satisfaction from developing a certain identity), but also to regulating and provisioning services. For instance, the rice harvest in particular in the mountain regions is valued primarily for the ESB of feeding people, but also for its taste and the fact that it, year after year, incorporates centuries of tradition, but not for its market value. Farmers usually do not sell it: although they could sell their rice at twice the market price of widespread high yielding varieties HYV, they prefer to consume the aromatic rice and look for additional income if necessary-like someone who will not sell grandfather's watch at whatever price. This became obvious in several of our study regions, in Ifugao, Philippines (where some family members have to work parts of the year to generate income to stock up the supply from one harvest a year) as well as in Hai Duong and Vinh Phuc, Vietnam where farmers keep the "aromatic" rice from the two or three harvests a year for the family and make a living on selling HYV rice planted on the area not needed for family consumption. These Ifugao farmers have decided to enjoy the use value, while their Vietnamese counterparts produce both use value, and exchange value, the money they get for what they sell, with the price dependent on supply and demand.

\section{Discussion and conclusions}

\section{Discussion}

LEGATO was a large-scale 5-year research project encompassing 20 contract partners from 6 countries and two international organisations as core members; in addition, there are numerous associated partners (Settele et al. 2015, and this issue). Aimed at advancing the long-term sustainable development of irrigated rice landscapes in South East Asia against risks arising from multiple aspects of global change, it deals with "complex societal problems associated with managing human-natural systems" and thus "requires research approaches that mirror the complexity of these systems" (Morton et al. 2015: 1) (Fig. 13). With its objective to initiate lasting change on the ground its ambition is to provide not only "transformation science" analysing transformation processes, but also "transformative science" enabling and facilitating change (WBGU 2011). The resulting need to collaborate amongst heterogeneous groups of scientists from different disciplines, and in particular with a range of stakeholders representing different, potentially diverging interests is a particular challenge (Görg et al. 2014; Spangenberg et al. 2015b). To deal with it, four pillars have been decisive: (1) a preproject exploration phase in which science-stakeholder contacts were established, preliminary research hypotheses refined by stakeholder input and research questions agreed, thus proving for an early integration of two types of knowledge, disciplinary and stakeholder knowledge: (2) a flexible 


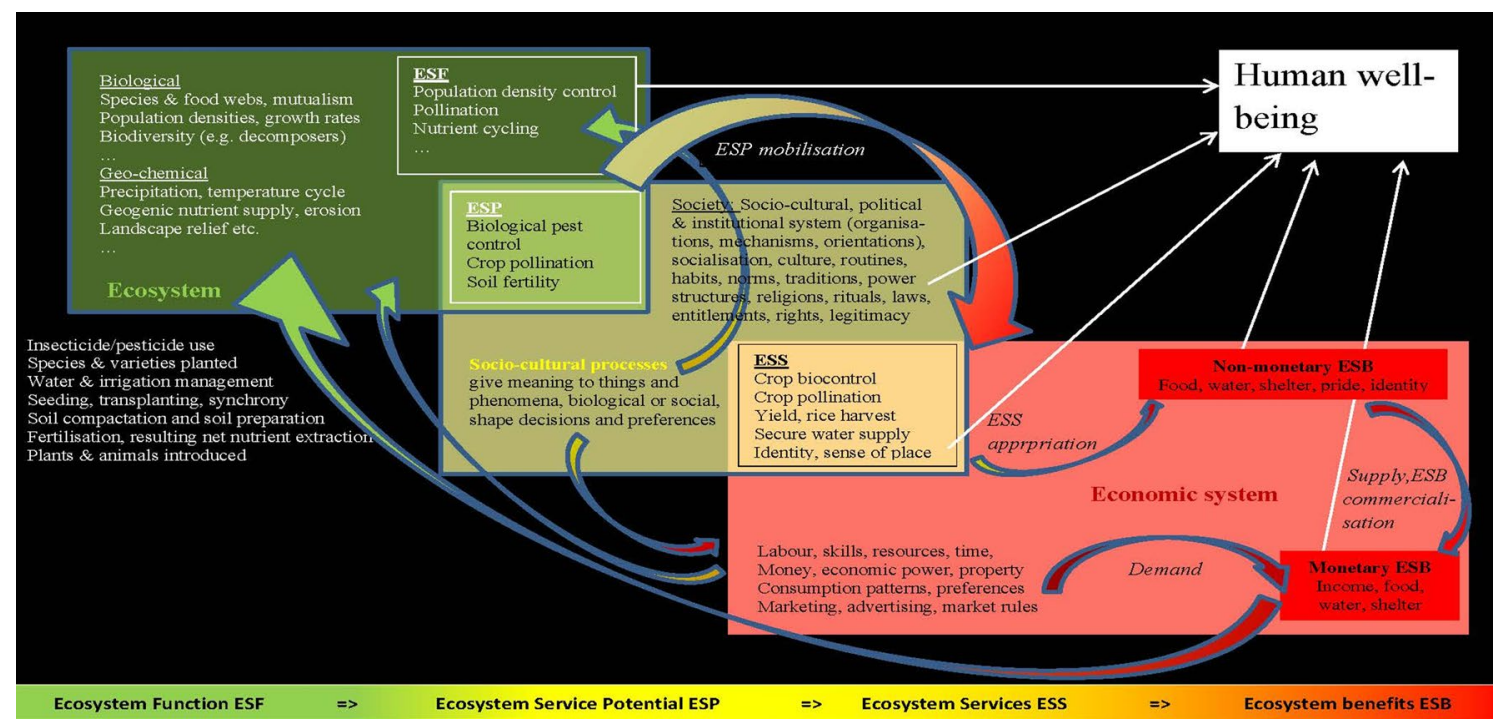

Fig. 13 Synthesis-unpacking the black box. Integrating the individual components, the influences linking inputs and outputs of the socio-environmental metasystem become visible, including positive

coordination, adaptable to bottom-up developments such as new research questions or stakeholder demands which were integrated throughout the project, able to deal with different intra- and interdisciplinary forms of work in project subgroups, motivating them to integrate into the larger transdisciplinary frame, contributing to the joint knowledge on system relationships presented in this paper, and leading negotiations over definitions and methods to identify which factors matter, what has to be measured how, and who has to be involved (Morton et al. 2015); (3) a joint concept for implementing the research findings, ecological engineering, which however evolved by being adapted to local situations and growing insights in the course of the project; and (4) the bridge concept of ecosystem services which permits to describe the overall results of the diverse research contributions in a unified language, without giving up the possibility to have detailed description in disciplinary parlance (Braat and de Groot 2012).

The ESS concept has been praised as causing a "renaissance in the conservation community" (Daily and Matson 2008: 9455). The claim that ecosystem services preservation is necessarily supportive to biodiversity conservation (Daily 1997; Costanza and Farber 2002; Barkman et al. 2008; Tallis et al. 2014; Deliège and Neuteleers 2015) turns the biologically founded assumption "biodiversity supports ecosystem service provision" on its head (prominently for instance Daily et al. 2009). Although reading a supposed causality in the opposite direction is of questionable logic, a positive correlation could be shown to exist in a number of cases for the specific situation of restoring degraded ecosystems (Polasky et al. 2012; Rey Benayas et al. 2009). and negative feedback loops. This way the figure points to the complexities of managing ecosystems for human well-being which are hidden behind the ESS cascade heuristics

In other cases, however, while biodiversity conservation safeguarding ESS provision could be shown, preserving ecosystem services was found not to safeguard biodiversity (Mumby et al. 2008). This resembles the situation we found in the LEGATO agricultural landscapes, and in rice monocultures in particular, where high biodiversity in the immediate vicinity of the fields has an important regulatory function in relation to pest outbreaks (Heong et al. 2015; Gurr et al. 2011; Heong 2009), while human interventions (especially insecticides) replace or at least suppress natural regulation mechanisms and in the course tend to reduce biodiversity. While maximising one ecosystem service (harvest), this strategy impinges on other service potentials and undermines the resilience of the system, paving the way for later infestations coming at significant monetary and social cost. Reliance on pesticides then often turns into a reality blinder; consequently, not less but more insecticides are used aggravating the problem (Spangenberg et al. 2015a).

Although ESS and biodiversity conservation are not identical, the ESS concept, in particular the ESS cascade including human agency, turned out to be a bridge concept providing a heuristics helpful in integrating the results from a wide range of disciplines in natural, social and cultural sciences. However, it took an extended discourse steered by the project coordination to arrive at a joint understanding of terms and concepts-for economists it is no way self-explaining that ESF are not defined as the biophysical base of ESS but as entities analysed by natural sciences for their functions irrespective of any utility criterion. For natural scientists it was not obvious that ESP are not natural 
phenomena but defined by human intervention, reflecting societal power structures. However, the social and political conflicts over their definition illustrate that indeed, ESP are culture-dependent anthropogenic constructs. ESS are thus generated in a co-production process of ecosystems and society; they are by no means free gifts of nature. How their value is defined, whether they are individually or collectively enjoyed, or commodified and traded depends on the preferences, habits and routines of the respective society and its economic system.

According to Reed et al. (2014), five steps need to be taken to assure lasting impact of a project. The first three steps (design, representation, engagement) have been part of the LEGATO project design from the outset (Görg et al. 2014). The fourth step "generate impact" has been the identification of land use and landscape features which promote ESF and ESS and the suggestions derived on how management or landscapes could be modified to increase ESF/ESS. Anticipating some of the results, but to a large extent based upon data from previous research, LEGATO initiated a first demonstration activity by establishing field sites under ecological engineering management (which at the first stage is just the planting of flowers near to rice fields, see Normille 2013; Gurr et al. 2016), initiated and accompanied through on-the-ground training. A further impact already generated within LEGATO is the TV series developed in collaboration with the Southern Plant Protection Centre and the Vietnam Long An TV station (Westphal et al. 2015).

It is the fifth step "reflect and sustain" which causes concerns, as it requires long-term relationships and learning processes, monitoring and reflection. This in turn requires sustaining the knowledge exchange even after project funding has ended-a serious challenge, in particular as an increasing share of research is undertaken in the form of fixed term projects which mitigates against such long-term engagement (it would be a misuse of the next project's funds, unless explicitly included there-which is a generally very rare event). It remains to be seen whether private contacts, meetings at conferences, etc., foreseen as the basis for continued contact can sufficiently substitute for such a permanent exchange and learning process. Ultimately benefits will only be sustained by the ongoing efforts of principle actors incentivised by realised ESB.

\section{Conclusions}

Based on the LEGATO experience, but supported by insight from earlier large-scale research projects, a number of conclusions can be drawn. They relate to the way a project is designed and conducted, and in particular to the (often underestimated) role of communication for the success of research projects and their lasting impact.
Science: beyond disciplinary knowledge

The complex nature of the interactions between ecogenic and anthropogenic factors in determining ESS is clearly beyond what any single discipline can apprehend. Thus, multiple disciplines have to collaborate, but in order to do so, they have to find their place in the broader context of the research question. Different disciplinary languages must be recognised as either complementary (shedding light on different aspects of the same issue), redundant (describing the same facts in different terminology) or contradictory (if a disciplinary description includes assumptions in contradiction to the secured body of knowledge of another discipline in charge of the issue). In the latter case, intradisciplinary adjustments are necessary to make disciplinary results “interdisciplinarity-ready" (Spangenberg 2011).

System relationships knowledge is necessary already in the project planning phase, but will be accumulated in the course of a project. It is essential to guide subunits of a larger project towards joint results, but often not adequately published due to the lack of specialised interdisciplinary journals and the trend to ever shorter papers which are hardly suitable to elaborate on complex, multidimensional interactions analysed by a diversity of disciplines. As a result, the integration efforts by interdisciplinary projects and their coordinators go often unrecognised, although they would be essential contributions to the new discipline of sustainability science. Project coordination is no technical task, but a scientific challenge (besides the omnipresent administrative duties).

Stakeholder analysis and the incorporation of stakeholder knowledge are essential for any transdisciplinary project and should best begin in a preproject phase, before the final application for funding is submitted. This can boost the relevance to the research questions for problem solving in the regions of analysis and potentially beyond. However, while stakeholder analysis and discursive knowledge integration may be an important issue in sociological and cultural anthropology journals, they are hard to publish in more natural science- or economics-oriented outlets, and vice versa. This creates a mismatch between the work done and the way the results can be published-which is a problem in particular for young researchers.

Science-policy-society interface: communication and co-operation

Communication is essential from the outset of any major transdisciplinary project: stakeholders have to know in advance what is demanded from them, and what they can expect from a project before they decide to join, or not to. A preproject preparation phase is extremely helpful in familiarising stakeholders with what scientific research can offer, and what are its limits. Already in this phase expectation management has to start: a project and its staff will 
immediately become part of existing conflicts, not as a matter of choice but because a foreign funded project has a priori a certain reputation and credibility, and conflicting parties will try to benefit from the project in different ways (Falck and Spangenberg 2014; Förster et al. 2015). Understanding such social processes and choosing a position rather than being pushed into a certain corner is important for being able to conduct the work, in particular for the social science parts. In terms of communication it necessitates to first understand the expectations towards the project which the communication about it has been raising, and to sensibly correct them. In LEGATO, potential conflict arenas to be observed include the roles of farmers and farm workers, or the partly complementary, partly competing role of sustained rice agriculture and expanding tourism.

The potentials as well as the limits of what science can contribute should be made clear from the outset. By analysing system dynamics, natural science is able to inform conscious judgements regarding sustainable levels and patterns of ESP use, understood here as modes of use not overburdening the system's capacity to reliable deliver ESS for an extended period of time, and to point out where the necessity for conscious judgement has been insufficiently realised so far. Then it is up to the society's institutional systems- - not to the scientists - to decide whether the system configuration (and potential changes) is a serious enough concern to justify the efforts necessary to avoid it, for instance due to the loss of ESF and thus the ESS provided by mobilising the ESP based on the ESF. If so, the potential damages are considered societally unacceptable (a consequentialist view), and the institutions are called upon to provide a framework preventing a system flip. The concept of ecological engineering has proven helpful in LEGATO in that is combines a scientific base with normative elements, i.e. the orientation towards sustainable agriculture, which was shared by scientists and stakeholders.

While social and cultural science analyse the interaction of natural and sociocultural, economic and political factors, natural science has to answer "if ... then ..." questions, trying to assess the future implications of taking certain actions, or not. The permanent underestimation of climate risks by the IPCC (each report referred to previously underestimated or unknown factors) illustrates how difficult this is. Nonetheless it is necessary, but only together the disciplines can provide a realistic conceptual basis for integrating results into an analytical scheme which as far as possible avoids the simplifications dominating the ESS literature so far, providing a basis for land use management decisions as solid as currently possible.

In Vietnam this approach has been complemented by producing a TV series, developed in collaboration with the Southern Plant Protection Centre and the Vietnam Long An TV station, with local actors explaining the benefits of ecological engineering in a sitcom format (Westphal et al. 2015). It was based on the earlier experience that media campaigns can be effective tools to modify farmer behaviour (Escalada et al. 1999).

A specific case is the situation at the end of a research project, not least due to the usually rather limited duration of research projects, while the complexity of the socio-environmental system and its in-built delays suggest that effecting change so as to enhance ESBs and/or their resilience requires sustained engagement with both ecosystems and human society. As research projects last only for a rather short period of time compared for instance with development programmes, national and international alike, preparing for the post-project period is an essential task of projects. Since more often than not it is uncertain if local stakeholders will be able to continue with what has been achieved after a project has ended, communicating clearly and early the future division of responsibility, the stepwise shift towards local stakeholders is a necessary part of the exit strategy each project should develop. The LEGATO exit strategy is based on three key components: (1) the ecological engineering training should enable farmers with the skills to continue the practice after the end of the project (empowerment), in particular given the economic benefits the approach provides them with (2) the support of authorities (in particular in Vietnam) which makes it easier to practice innovative land management methods and (3) the offer of low level, but still continued support from the scientific partners in the host countries, and in cases of emergency from some of the German partners as well (all without being funded for that).

Funding This study was funded by the German Federal Ministry of Education and Research (BMBF) within the BMBF-Funding Measure "Sustainable Land Management" (Grant Number FKZ01LL0917A01LL0917O, 2010-2016).

\section{Compliance with ethical standards}

Conflict of interest The authors declare that they have no conflict of interest.

Open Access This article is distributed under the terms of the Creative Commons Attribution 4.0 International License (http://creativecommons.org/licenses/by/4.0/), which permits unrestricted use, distribution, and reproduction in any medium, provided you give appropriate credit to the original author(s) and the source, provide a link to the Creative Commons license, and indicate if changes were made. 


\section{Appendix: Glossary (modified from Harrington et al. 2010, if not otherwise indicated)}

Biodiversity/biological diversity: The diversity of any level of biological organisations, i.e. genetic, species, populations, communities, ecosystems, functions and phylogenetic relationships. Sometimes this may also include associated abiotic components such landscape features (based on geological diversity, land use and land management) as well as climate (Kühn, definition for the project).

Biodiversity-Ecosystem functioning relationship BEF: The link between biodiversity and ecosystem functioning (from Reiss et al. 2009).

Community: An association of interacting populations of different species, usually defined by the nature of their interactions or by the place in which they live.

DART The Dynamic Applied Regional Trade model: A computable general equilibrium model of the world economy that accounts for socio-economic developments, such as population growth and changes in consumption patterns, and repercussions between different production sectors and regions, simulating the development of crop quantity and prices (LEGATO).

Ecological Engineering: Managing ecosystems to enhance ecosystem benefit generation by exploiting ecosystem processes and functions instead of suppressing them through management means, thus minimising, for example, pesticide use (Gurr et al. 2011).

Ecosystem: A dynamic complex of plant, animal, fungal and microorganism communities and their abiotic environment interacting as a functional unit (MA 2003). Humans, where present, are an integral part of ecosystems.

Ecosystem benefits ESB: The contributions of ecosystem services to the support of human survival and quality of life.

Ecosystem function ESF: An intrinsic ecosystem characteristic related to the set of elements, conditions and processes whereby an ecosystem maintains its integrity (MA 2003). Examples of ecosystem functions include primary productivity and biogeochemical cycles. Some authors use the term ecosystem property for it (from Reiss et al. 2009).
Ecosystem functioning: The joint effect of all ecosystem functions that sustain an ecosystem (adapted from Reiss et al. 2009).

Ecosystem processes: The interactions (events, reactions or operations) among biotic and abiotic elements of ecosystems which underlie an ecosystem function. Examples of ecosystem processes include photosynthesis and nutrient uptake.

Ecosystem services ESS: The ecosystem structures, processes and outputs that humans recognise as obtained from ecosystems that can support, directly or indirectly, their survival and quality of life (extended from MA 2003).

Ecosystem Service Beneficiary: A stakeholder who benefits directly from a biological or physical resource, ecosystem service, institution, or social system, or someone who is or may be affected positively by a public policy.

Ecosystem service potential ESP: The recognised range of potential use of structures, processes and outputs of ecosystems, including multiple and possibly rival uses. The ESP imagined depend on the specific situation, and on the group attributing the use value (Spangenberg 2014).

Exchange value: The value a tradable good or service generates by exchanging it for some other good, usually measured in monetary terms.

Functional diversity: The range, actual values and relative abundance of functional trait attributes in a given community.

Functional group, functional type: A collection of organisms with similar functional trait attributes. Groups can be associated with similar responses to pressures and/or effects on ecosystem processes.

Functional trait: A feature of an organism, which has demonstrable links to the organism's function.

Functional trait attribute: The value/state of a functional trait.

GCMs General Circulation Models: A numerical representation of the climate system based on the physical, chemical and biological properties of its components, their interactions and feedback processes, and accounting for some of its known properties (IPCC AR5).

Guild: A functional group in particular of animals, e.g. groups sharing the same feeding types and thus having the 
same function within the trophic chain: the group (guild) predating on a specific pest.

Habitat: The habitat of a species, or population of a species, is the sum of the abiotic and biotic factors of the environment, whether natural or modified, which are essential to the life and reproduction of the species within its natural geographical range.

Institutions: Durable systems of established and embedded social rules (convention, norms and legal rules) that structure social interaction. Institutions regulate relationships among people and between social and ecological systems.

Landscape: A heterogeneous mosaic of habitat patches, physical conditions or other spatially variable elements viewed at scales relevant to the organisms or processes under consideration. It includes human features such as arable fields, forests, and cities.

Real (= objective) value: Value determined by the inherent characteristics of an object, often based on scientific criteria (e.g. rarity).

Social-Ecological System (sometimes referred to as a "Socio-ecological System"): A system that includes societal (human) and ecological (biophysical) subsystems in mutual interactions and thus captures interactions between ecosystems, biodiversity and people.

SRES emission scenarios: $\mathrm{CO}_{2}$ emission scenarios until 2100, published in 2000 in the "Special Report on Emission Scenarios". "A set of scenarios [...] to represent the range of driving forces and emissions in the scenario literature so as to reflect current understanding and knowledge about underlying uncertainties" (Nakićenović et al. 2000).

Stakeholder: A person having a stake or interest in a biological or physical resource, ecosystem service, institution or social system, or someone who is or may be affected by a public policy (adapted from MA 2003).

Subjective value: Value allocated to an object based on individual or collective human decisions based on preferences and, if possible, quantified on the basis of the intensity of these preferences.

Use value: Value derived from some interaction with the resource, either directly or indirectly.

Valuation: The process of assigning importance and necessity to objects and actions.
Value: The importance and necessity of objects and actions. Several categories of value have been defined: ideal (including ethical), real (= objective) (including ecological) and subjective (including economic, aesthetic, and cultural).

\section{References}

Adams WM (2014) The value of valuing nature. Science 346(6209):549-551

Backhaus N (2011) Landscapes, spatial totalities or special regions?. Procedia-Social Behav Sci 14:193-202

Bardgett RD (2005) The biology of soil: a community and ecosystem approach. Oxford University Press, Oxford

Bardgett RD, van der Putten WH (2014) Belowground biodiversity and ecosystem functioning. Nature 515:505-511

Barkman J, Glenk K, Keil A, Leemhuis C, Dietrich N, Gerold G, Marggraf R (2008) Confronting unfamiliarity with ecosystem functions: the case for an ecosystem service approach to environmental valuation with stated preference methods. Ecol Econ 65(1):48-62

Barrios E (2007) Soil biota, ecosystem services and land productivity. Ecol Econ 64:269-285

Basu S, Leeuwis C (2012) Understanding the rapid spread of System of Rice Intensification (SRI) in Andhra Pradesh: exploring the building of support networks and media representation. Agric Syst 111:34-44

Bayon R, Jenkins M (2010) The business of biodiversity. Nature 466(7303):184-185

Beare MH, Reddy MV, Tian G, Srivastava SC (1997) Agricultural intensification, soil biodiversity and agroecosystem function in the tropics: the role of decomposer biota. Appl Soil Ecol 6:87-108

Bengtsson J (2015) Biological control as an ecosystem service: partitioning contributions of nature and human inputs to yield. Ecol Entomol 40:45-55

Bianchi FJJA, Booij CJH, Tscharntke T (2006) Sustainable pest regulation in agricultural landscapes: a review on landscape composition, biodiversity and natural pest control. Proc Biol Sci 273:1715-1727

Billeter R, Liira J, Bailey D, Bugter R, Arens P, Augenstein I, Aviron S, Baudry J, Bukacek R, Burel F, Cerny M, de Blust G, de Cock R, Diekotter T, Dietz H, Dirksen J, Dormann C, Durka W, Frenzel M, Hamersky R, Hendrickx F, Herzog F, Klotz S, Koolstra B, Lausch A, Le Coeur D, Maelfait JP, Opdam P, Roubalova M, Schermann A, Schermann N, Schmidt T, Schweiger O, Smulders MJM, Speelmans M, Simova P, Verboom J, van Wingerden W, Zobel M, Edwards PJ (2008) Indicators for biodiversity in agricultural landscapes: a pan-European study. J Appl Ecol 45:141-150

Birkhofer K, Bezemer TM, Bloem J, Bonkowski M, Christensen S, Dubois D, Ekelund F, Fliessbach A, Gunst L, Hedlund K, Mader P, Mikola J, Robin C, Setala H, Tatin-Froux F, van der Putten WH, Scheu S (2008) Long-term organic farming fosters below and aboveground biota: implications for soil quality, biological control and productivity. Soil Biol Biochem 40:2297-2308

Bondeau A, Smith PC, Zaehle S, Schaphoff S, Lucht W, Cramer W, Gerten D, Lotze-Campen H, Müller C, Reichstein M, Smith B (2007) Modelling the role of agriculture for the 20th century global terrestrial carbon balance. Glob Change Biol 13(3):679-706

Bottrell DG, Schoenly KG (2012) Resurrecting the ghost of green revolutions past: the brown planthopper as a recurring threat to 
high-yielding rice production in tropical Asia. J Asia Pac Entomol 15:122-140

Boyd J, Banzhaf S (2007) What are ecosystem services? The need for standardized environmental accounting units. Ecol Econ 63(2-3):616-626

Braat LC, de Groot R (2012) The ecosystem services agenda: bridging the worlds of natural science and economics, conservation and development, and public and private policy. Ecosyst Serv 1(1):4-15

Brady M, Hedlund K, Cong R-G, Hemerik L, Hotes S, Mattsson L, Schulz E, Thomsen IK (2015) Valuing soil natural capital in agriculture. Agron J 107:1809-1821

Brittain C, Potts S (2012) The potential impacts of insecticides on the life-history traits of bees and the consequences for pollination. Basic Appl Ecol 12(4):321-331

Burkhard B, Kroll F, Nedkov S, Müller F (2012) Mapping supply, demand and budgets of ecosystem services. Ecol Ind 21:17-29

Burkhard B, Müller A, Müller F, Grescho V, Anh Q, Arida G, Bustamante JV, Van Chien H, Heong KL, Escalada M, Marquez L, Thanh Truong D, Villareal S, Settele J (2015) Land cover-based ecosystem service assessment of irrigated rice cropping systems in Southeast Asia-an explorative study. Ecosyst Serv 14:76-87

Calzadilla A, Delzeit R, Klepper G (2014) DART-BIO: modelling the interplay of food, feed and fuels in a global CGE model. Kiel Working Paper no. 1896. Kiel Institute for the World Economy, Kiel, Germany. https://www.ifw-members.ifw-kiel.de/publications/dart-bio-modelling-the-interplay-of-food-feed-and-fuelsin-a-global-cge-model/KWP1896.pdf. Accessed 1 June 2015

Chakravarthy AK (1987) Insect pests on main and ratoon rice. Int Rice Res Newsl 12(4):35-36

Coeterier JF (1996) Dominant attributes in the perception and evaluation of the Dutch landscape. Landsc Urban Plan 34(1):27-44

Creamer RE, Hannula SE, Leeuwen, JPV, Stone, D, Rutgers M, Schmelz RM, Ruiter PCd, Hendriksen NB, Bolger T, Bouffaud ML, Buee M, Carvalho F, Costa D, Dirilgen T, Francisco R, Griffiths BS, Griffiths R, Martin F, Silva PMd, Mendes S, Morais PV, Pereira C, Philippot L, Plassart P, Redecker D, Römbke J, Sousa JP, Wouterse M, Lemanceau P (2016) Ecological network analysis reveals the inter-connection between soil biodiversity and ecosystem function as affected by land use across Europe. Appl Soil Ecol 97(Supplement C):112-124

Costanza R, Farber S (2002) Introduction to the special issue on the dynamics and value of ecosystem services: integrating economic and ecological perspectives. Ecol Econ 41(3):367-373

Daily GC (1997) Nature's services: societal dependence on natural ecosystems. Island Press, Washington

Daily GC, Matson PA (2008) Ecosystem services: from theory to implementation. Proc Natl Acad Sci 105(28):9455-9456

Daily GC, Polasky S, Goldstein J, Kareiv PM, Mooney HA, Pejchar L, Ricketts TH, Salzman J, Shallenberger R (2009) Ecosystem services in decision making: time to deliver. Front Ecol Environ $7(1): 21-28$

David CC, Ostuka K (eds) (1994) Modern rice technology and income distribution in Asia. Lynne Rienner Publishers, Boulder

de Groot R, Brander L, van der Ploeg S, Costanza R, Bernard F, Braat L, Christie M, Crossman N, Ghermandi A, Hein L, Hussain S, Kumar P, McVittie A, Portela R, Rodriguez LC, ten Brink P, van Beukering P (2012) Global estimates of the value of ecosystems and their services in monetary units. Ecosyst Serv 1(1):50-61

de Oliveira LEC, Berkes F (2014) What value São Pedro's procession? Ecosystem services from local people's perceptions. Ecol Econ 107:114-121

de Vries FT, Thebault E, Liiri M, Birkhofer K, Tsiafouli MA, Bjornlund L, Jorgensen HB, Brady MV, Christensen S, de Ruiter PC, d'Hertefeldt T, Frouz J, Hedlund K, Hemerik L, Hol WHG, Hotes S, Mortimer SR, Setala H, Sgardelis SP, Uteseny K, van der Putten WH, Wolters V, Bardgett RD (2013) Soil food web properties explain ecosystem services across European land use systems. PNAS 110:14296-14301

Deliège G, Neuteleers S (2015) Should biodiversity be useful? Scope and limits of ecosystem services as an argument for biodiversity conservation. Environ Values 24(2):165-182

Delzeit R, Zabel F, Meyer C, Václavík T (2017) Addressing future trade-offs between biodiversity and cropland expansion to improve food security. Reg Environ Change. https://doi. org/10.1007/s10113-016-0927-1

Dominati E, Mackay A, Green S, Patterson M (2014) A soil changebased methodology for the quantification and valuation of ecosystem services from agro-ecosystems: a case study of pastoral agriculture in New Zealand. Ecol Econ 100:119-129

Dominik C, Seppelt R, Horgan FG, Marquez L, Settele J, Václavík T (2017) Regional-scale effects override the influence of fine-scale landscape heterogeneity on rice arthropod communities. Agric Ecosyst Environ 246:269-278

Dungait JA, Hopkins DW, Gregory AS, Whitmore AP (2012) Soil organic matter turnover is governed by accessibility not recalcitrance. Glob Change Biol 18:1781-1796

Ericksen PJ, Ingram JSI, Liverman DM (2009) Food security and global environmental change: emerging challenges. Environ Sci Policy 12(4):373-377

Escalada M, Heong KL, Huan N, Mai V (1999) Communication and behavior change in rice farmers' pest management: the case of using mass media in Vietnam. J Appl Commun 83(1):7-26

Fagerholm N, Käyhkö N, Ndumbaro F, Khamis M (2012) Community stakeholders' knowledge in landscape assessments - Mapping indicators for landscape services. Ecol Indic 18(Supplement C):421-433

Falck WE, Spangenberg JH (2014) Selection of social demandbased indicators: EO-based indicators for mining. J Clean Prod 84:193-203

Fisher B, Turner RK, Morling P (2009) Defining and classifying ecosystem services for decision making. Ecol Econ 68(3):643-653

Flohre A, Rudnick M, Traser G, Tscharntke T, Eggers T (2011) Does soil biota benefit from organic farming in complex vs. simple landscapes? Agric Ecosyst Environ 141:210-214

Förster J, Barkmann J, Fricke R, Hotes S, Kleyer M, Kobbe S, Kübler D, Rumbaur C, Siegmund-Schultze M, Seppelt R, Settele J, Spangenberg JH, Tekken V, Vaclavik T, Wittmer H (2015) Assessing ecosystem services for informing land-use decisions: a problem-oriented approach. Ecol Soc 20(3):31

Fox J, Vogler J (2005) Land-use and land-cover change in montane mainland Southeast Asia. Environ Manag 36(3):394-403

Fried O, Kühn I, Schrader J, Nguyen VS, Bergmeier E (2017) Plant diversity and community composition of rice agroecosystems in Vietnam and the Philippines. Phytocoenologia. https://doi. org/10.1127/phyto/2016/0123

García-Palacios P, Maestre FT, Kattge J, Wall DH (2013) Climate and litter quality differently modulate the effects of soil fauna on litter decomposition across biomes. Ecol Lett 16:1045-1053

Garibaldi LA, Carvalheiro LG, Leonhardt SD, Aizen MA, Blaauw BR, Isaacs R, Kuhlmann M, Kleijn D, Klein AM, Kremen C, Morandin L, Scheper J, Winfree R (2014) From research to action: enhancing crop yield through wild pollinators. Front Ecol Environ 12(8):439-447

Gerlach J, Samways M, Pryke J (2013) Terrestrial invertebrates as bioindicators: an overview of available taxonomic groups. J Insect Conserv 17:831-850

Gerten D, Schaphoff S, Haberlandt U, Lucht W, Sitch S (2004) Terrestrial vegetation and water balance-hydrological evaluation of a dynamic global vegetation model. J Hydrol 286:249-270

Godfray HCJ, Beddington JR, Crute IR, Haddad L, Lawrence D, Muir JF, Pretty J, Robinson S, Thomas SM, Toulmin C (2010) 
Food security: the challenge of feeding 9 billion people. Science 327(5967):812-818

Gómez-Baggethun E, Ruiz-Pérez M (2011) Economic valuation and the commodification of ecosystem services. Prog Phys Geogr 35(5):613-628

Gómez-Baggethun E, De Groot R, Lomas PL, Montes C (2010) The history of ecosystem services in economic theory and practice: from early notions to markets and payment schemes. Ecol Econ 69(6):1209-1218

Görg C, Aicher C (2014) Ökosystemdienstleistungen-zwischen Natur und Gesellschaft. Anforderungen an eine inter- und transdisziplinäre Forschung aus Sicht der Sozialwissenschaften, Veröffentlichungen der Berlin-Brandenburgischen Akademie der Wissenschaften, Berichte und Abhandlungen Band 16, De Gruyter-Akademie Verlag, Berlin, 35-58

Görg C, Spangenberg JH, Tekken V, Burkhard B, Truong Dao Thanh, Escalada M, Heong KL, Arida G, Marquez LV, Bustamante JV, Van Chien Ho, Klotzbücher T, Marxen A, Manh Nguyen Hung, Van Sinh Nguyen, Villareal S, Settele J (2014) engaging local knowledge in biodiversity research: experiences from large interand transdisciplinary projects. Interdiscip Sci Rev 39(4):323-341

Grace JB, Anderson TM, Seabloom EW, Borer ET, Adler PB, Harpole WS, Hautier Y, Hillebrand H, Lind EM, Pärtel M, Bakker JD, Buckley YM, Crawley MJ, Damschen EI, Davies KF, Fay PA, Firn J, Gruner DS, Hector A, Knops JMH, MacDougall AS, Melbourne BA, Morgan JW, Orrock JL, Prober SM, Smith MD (2016) Integrative modelling reveals mechanisms linking productivity and plant species richness. Nature 529(7586):390-393

Guntzer F, Keller C, Meunier J-D (2009) Benefits of plant silicon for crops: a review. Agron Sustain Dev 32:201-213

Gurr GM, Liu J, Read DMY, Catindig JLA, Cheng JA, Lan LP, Heong KL (2011) Parasitoids of Asian rice planthopper (Hemiptera: Delphacidae) pests and prospects for enhancing biological control by ecological engineering. Ann Appl Biol 158:149-176

Gurr GM, Zhongxian L, Xusong Z, Hongxing X, Pingyang Z, Guihua C, Xiaoming Y, Cheng J, Zengrong Z, Catindig JL, Villareal S, Van Ho C, Le Quoc C, Channoo C, Chengwattana N, La Pham L, Le Huu H, Chaiwong J, Nicol HI, Perovic DJ, Wratten SD, Heong KL (2016) Multi-country evidence that crop diversification promotes ecological intensification of agriculture. Nat Plants, 22.2.2016, Art.16014

Haberl H, Gaube V, Díaz-Delgado R, Krauze K, Neuner A, Peterseil J, Plutzar C, Singh SJ, Vadineanu A (2009) Towards an integrated model of socioeconomic biodiversity drivers, pressures and impacts. A feasibility study based on three European long-term socio-ecological research platforms. Ecol Econ 68:1797-1812

Haines-Young R, Potschin M, Kienast F (2012) Indicators of ecosystem service potential at European scales: mapping marginal changes and trade-offs. Ecol Ind 21:39-53

Harrington R, Anton C, Dawson T, de Bello F, Feld C, Haslett J, Kluvánkova-Oravská T, Kontogianni $\mathrm{A}$, Lavorel $\mathrm{S}$, Luck $\mathrm{G}$, Rounsevell M, Samways M, Settele J, Skourtos M, Spangenberg JH, Vandewalle M, Zobel M, Harrison P (2010) Ecosystem services and biodiversity conservation: concepts and a glossary. Biodivers Conserv 19:2773-2790

Harrison PA, Berry PM, Simpson G, HaslettJR Blicharska M, Bucur M, Dunford R, Egoh B, Garcia-Llorente M, Geamănă N, Geertsema W, Lommelen E, Meiresonne L, Turkelboom F (2014) Linkages between biodiversity attributes and ecosystem services: a systematic review. Ecosyst Serv 9:191-203

Hauck J, Görg C, Werner A, Jax K, Bidoglio G, Maes J, Furman E, Ratamäki O (2014) transdisciplinary enrichment of a linear research process: experiences gathered from a research project supporting the European biodiversity strategy to 2020. Interdiscip Sci Rev 39(4):376-391
Hautier Y, Tilman D, Forest I, Seabloom EW, Borer ET, Reich PB (2015) Anthropogenic environmental changes affect ecosystem stability via biodiversity. Science 348:336-340

Heong KL (2009) Are planthopper problems caused by a breakdown in ecosystem services? In: Heong KL, Hardy B (eds) Planthoppers: new threats to the sustainability of intensive rice production systems in Asia. IRRI (International Rice Research Institute), Los Baños, pp 221-232

Heong KL, Hardy B (eds) (2009) Planthoppers: new threats to the sustainability of intensive rice production systems in Asia. IRRI International Rice Research Institute, Los Baños

Heong KL, Aquino GB, Barrion AT (1991) Arthropod community structures of rice ecosystems in the Philippines. Bull Entomol Res 81:407-416

Heong KL, Escalada MM, Huan NH, Chien HV, Quynh PV (2010) Scaling out communication to rural farmers-lessons from the "Three Reductions, Three Gains" campaign in Vietnam. In: Palis FG, Singleton GR, Casimero MC, Hardy B (eds) Research to impact: case studies for natural resource management for irrigated rice in Asia. IRRI International Rice Research Institute, Los Baños, pp 207-220

Heong KL, Chien HV, Escalada MM, Trébuil G (2013) Réduction de l'usage des insecticides dans la riziculture irriguée d'Asie du Sud-Est: de l'écologie expérimentale au changement des pratiques à grande échelle. Cah Agric 22:1-7

Heong KL, Escalada MM, Chien HV, Cuong LQ (2014) Restoration of rice landscape biodiversity by farmers in Vietnam through education and motivation using media. SAPIENS 7(2):29-35

Heong KL, Wong L, de los Reyes JH (2015) Addressing planthopper threats to Asian rice farming and food security: fixing insecticide misuse. In: Heong KL, Cheng J, Escalada MM (eds) Rice planthoppers. Springer, Amsterdam, pp 65-76

Hertz T, Schlüter M (2015) The SES-framework as boundary object to address theory orientation in social-ecological system research: the SES-TheOr approach. Ecol Econ 116:12-24

Hoai PM, Sebesvari Z, Minh TB, Viet PH, Renaud FG (2011) Pesticide pollution in agricultural areas of Northern Vietnam: case study in Hoang Liet and Minh Dai communes. Environ Pollut 159(12):3344-3350

Hokema D (2012) Landschaft im Wandel?: Zeitgenössische Landschaftsbegriffe in Wissenschaft, Planung und Alltag. Springer-Verlag

Holt J, Chancellor TCB, Reynolds DR, Tiongco ER (1996) Risk assessment for rice planthopper and tungro disease outbreaks. Crop Prot 15:359-368

Hooper DU, Adair EC, Cardinale BJ, Byrnes JEK, Hungate BA, Matulich KL, Gonzalez A, Duffy JE, Gamfeldt L, O'Connor MI (2012) A global synthesis reveals biodiversity loss as a major driver of ecosystem change. Nature 486(7401):105-108

Horgan FG, Stuart AM, Kudavidanage EP (2014) Impact of invasive apple snails on the functioning and services of natural and managed wetlands. Acta Oecol 54:90-100

Huan NH, Thiet LV, Chien HV, Heong KL (2005) Farmers' evaluation of reducing pesticides, fertilizers and seed rates in rice farming through participatory research in the Mekong Delta, Vietnam. Crop Prot 24:457-464

Islam Z, Heong KL, Catling D, Kritani K (2012) Invertebrates in rice production systems: status and trends. FAO Food and Agriculture Organization of the United Nations, Commission on Genetic Resources for Food and Agriculture. Background study paper no. 62

IUCN CEM World Conservation Union Commission on Ecosystem Management (2006) Biodiversity and livelihoods. IUCN, Gland

Ives AR, Carpenter SR (2007) Stability and diversity of ecosystems. Science 317:58-62 
Jenny H (1941) Factors of soil formation: a system of quantitative pedology. McGraw-Hill, New York

Jones L, Norton L, Austin Z, Browne AL, Donovan D, Emmett BA, Grabowski ZJ, Howard DC, Jones JPG, Kenter JO, Manley W, Morris C, Robinson DA, Short C, Siriwardena GM, Stevens CJ, Storkey J, Waters RD, Willis GF (2016) Stocks and flows of natural and human-derived capital in ecosystem services. Land Use Policy 52:151-162

Kessler M, Abrahamczyk S, Bos M, Buchori D, Putra DD, Gradstein SR, Hohn P, Kluge J, Orend F, Pi-topang R, Saleh S, Schulze CH, Sporn SG, Steffan-Dewenter I, Tjitrosoedirdjo SS, Tscharntke T (2011) Cost-effectiveness of plant and animal biodiversity indicators in tropical forest and agroforest habitats. J Appl Ecol 48(2):330-339

Klotzbücher T, Marxen A, Vetterlein D, Schneiker J, Türke M, Sinh NV, Manh NH, Chien HV, Marquez L, Villareal S, Bustamante JV, Jahn R (2015a) Plant-available silicon in paddy soils as a key factor for sustainable rice production in Southeast Asia. Basic Appl Ecol 16:665-673

Klotzbücher T, Leuther F, Marxen A, Vetterlein D, Horgan F, Jahn R (2015b) Forms and fluxes of po-tential plant-available silicon in irrigated lowland rice production (Laguna, the Philippines). Plant Soil 393:177-191

Klotzbücher T, Marxen A, Jahn R, Vetterlein D (2016) Silicon cycle in rice paddy fields: insights provided by relations between silicon forms in topsoils and plant silicon uptake. Nutr Cycl Agroecosyst 105:157-168

Kögel-Knabner I, Amelung W, Cao Z, Fiedler S, Frenzel P, Jahn R, Kalbitz K, Kölbl A, Schloter M (2010) Biogeochemistry of paddy soils. Geoderma 157:1-14

Koh LP (2007) Impacts of land use change on South-east Asian forest butterflies: a review. J Appl Ecol 44(4):703-713

Kremen C, Williams NM, Thorp RW (2002) Crop pollination from native bees at risk from agricultural intensification. PNAS 99(26): 16812-16816

Kühne O (2013) Landschaft im Diskurs: konstruktivistische Landschaftstheorie als Perspektive für künftigen Umgang mit Landschaft. Naturschutz und Landschaftsplanung 45(3)

Kumalasari NR, Bergmeier E (2014) Effects of surrounding crop and semi-natural vegetation on the plant diversity of paddy fields. Agric Food Secur 3:15

Kumalasari NR, Abdullah L, Bergmeier E (2014) Nutrient assessment of paddy weeds as ruminant feed in Java. Livest Res Rural Dev 26:59

Langerwisch F, Vaclavik T, Bloh Wv, Vetter T, Thonicke K (2017) Combined effects of climate and landuse change on the provision of ecosystem services in rice agro-ecosystems. Environ Res Lett. https://doi.org/10.1088/1748-9326/aa954d

Lefcheck JS, Byrnes JEK, Isbell F, Gamfeldt L, Griffin JN, Eisenhauer N, Hensel MJS, Hector A, Cardi-nale BJ, Duffy JE (2015) Biodiversity enhances ecosystem multifunctionality across trophic levels and habitats. Nat Commun 6

Lekha A, Chopra G, Gupta SR (1989) Role of soil fauna in decomposition of rice and sorghum straw. Proc Indian Acad Sci 98:275-284

Levin PS, Williams GD, Rehr A, Norman KC, Harvey CJ (2015) Developing conservation targets in social-ecological systems. Ecol Soc 20(4):art 6

Lu Z-X, Zhu P-Y, Gurr G, Zheng X-S, Read DMY, Heong KL, Yang Y-J, Xu H-X (2014) Mechanisms for flowering plants to benefit arthropod natural enemies of insect pests: prospects for enhanced use in agriculture. Insect Sci 21:1-12

MA Millennium Ecosystem Assessment (2003) Ecosystems and human well-being - a framework for assessment. Island Press, Washington
MA Millennium Ecosystem Assessment (2005) Ecosystems and human well-being: synthesis. Washington DC, Island Press

Martin EA, Reineking B, Seo B, Steffan-Dewenter I (2013) Natural enemy interactions constrain pest control in complex agricultural landscapes. PNAS 110(14):5534-5539

Marxen A, Klotzbücher T, Jahn R, Kaiser K, Nguyen VS, Schmidt A, Schädler M, Vetterlein D (2016) Interaction between silicon cycling and straw decomposition in a silicon deficient rice production system. Plant Soil 398:153-163

Massey D (1999) Spaces of politics. Hum Geogr Today 279:294

McShane TO, Hirsch PD, Trung TC, Songorwa AN, Kinzig A, Monteferri B, Mutekanga D, Thang HV, Dammert JL, Pulgar-Vidal M, Welch-Devine M, Peter Brosius J, Coppolillo P, O'Connor S (2011) Hard choices: making trade-offs between biodiversity conservation and human well-being. Biol Conserv 144(3):966-972

Meinard Y, Grill P (2011) The economic valuation of biodiversity as an abstract good. Ecol Econ 70(10):1707-1714

Mollinga PP (2010) Boundary work and the complexity of natural resources management. Crop Sci 50(Supplement 1):S1-S9

Morton LW, Eigenbrode SD, Martin TA (2015) Architectures of adaptive integration in large collaborative projects. Ecol Soc 20(4):art 5

Mumby PJ, Broad K, Brumbaugh DR, Dahlgren CP, Harborne AR, Hastings A, Holmes KE, Kappel CV, Micheli F, Sanchirico JN (2008) Coral reef habitats as surrogates of species, ecological functions, and ecosystem services. Conserv Biol 22(4):941-951

Muraca B (2011) The map of moral significance: a new axiological matrix for environmental ethics. Environ Values 20(3):375-396

Naidoo R, Balmford A, Costanza R, Fisher B, Green RE, Lehner B, Malcocolm TR, Ricketts TH (2008) Global mapping of ecosystem services and conservation priorities. Proc Natl Acad Sci 105(28):9495-9500

Nakićenović N (2000) Greenhouse gas emissions scenarios. Technol Forecast Soc Change 65(2):149-166

Noltze M, Schwarze S, Qaim M (2013) Impacts of natural resource management technologies on agricultural yield and household income: the system of rice intensification in Timor Leste. Ecol Econ 85:59-68

Norgaard RB (2010) Ecosystem services: from eye-opening metaphor to complexity blinder. Ecol Econ 69(6):1219-1227

Normille D (2013) Vietnam turns back a tsunami of pesticides. Science 341:737-738

Norton GA, Heong KL, Cheng JA (2015) In: Heong KL, Cheng JA, Escalada MM (eds) Rice planthoppers: ecology, management, socio economics and policy. Zhejiang University Press, Hangzhou, China, Springer Science+Business Media, Dordrecht, Netherlands, pp 209-226

Ott J (2015) Libellen in Reisfeldern Asiens-nur bunte Dekoration oder ein wichtiger Bestandteil des Ökosystems? In: P Diehl, A Imhoff, L Möller L (eds) Wissensgesellschaft Pfalz-90 Jahre Pfälzische Gesellschaft zur Förderung der Wissenschaften. Verlag Regionalkultur, Ubstadt-Weiher, pp 327-334

Paoletti MG, Bressan M (1996) Soil invertebrates as bioindicators of human disturbance. Crit Rev Plant Sci 15:21-62

Peters K, Bundschuh M, Schafer B (2013) Review on the effects of toxicants on freshwater ecosystem functions. Environ Pollut 180:324-329

Pingali PL, Hossain M, Gerpacio Roberta V (1997) Asian Rice bowls: the returning crisis?. CABI International, Wallingford

Polasky S, Johnson K, Keele B, Kovacs K, Nelson E, Pennington D, Plantinga AJ, Withey J (2012) Are investments to promote biodiversity conservation and ecosystem services aligned? Oxf Rev Econ Policy 28(1):139-163

Potschin MB, Haines-Young RH (2011) Ecosystem services. Prog Phys Geogr 35(5):575-594 
Prasad C (2006) System of rice intensification in India: innovation history and institutional challenges. http://www.crispindia.org/ docs/sri. Accessed 12 Dec 2015

Prigogine I, Stengers I (1984) Order out of chaos: man's new dialogue with nature. Heinemann, Boulder

Pröpper M, Haupts F (2014) The culturality of ecosystem services. Emphasizing process and transformation. Ecol Econ 108:28-35

Pu D-Q, Shi M, Wu Q, Gao M-Q, Liu J-F, Ren S-P, Yang F, Tang P, Ye G-Y, Shen Z-C, He J-H, Yang D, Bu W-J, Zhang C-T, Song Q, Xu D, Strand MR, Chen X-X (2014) Flower-visiting insects and their potential impact on transgene flow in rice. J Appl Ecol 51:1357-1365

Pywell RF, Heard MS, Woodcock BA, Hinsley S, Ridding L, Nowakowski M, Bullock JM (2015) Wildlife-friendly farming increases crop yield: evidence for ecological intensification. Proc R Soc Lond B Biol Sci 282(1816):art 20151740

Reed MS, Stringer LC, Fazey I, Evely AC, Kruijsen JHJ (2014) Five principles for the practice of knowledge exchange in environmental management. J Environ Manag 146:337-345

Rees WE (1998) How should a parasite value its host? Ecol Econ 25(1):49-52

Reiss J, Bridle JR, Montoya JM, Woodward G (2009) Emerging horizons in biodiversity and ecosystem functioning research. Trends Ecol Evol 24(9):505-514

Rey Benayas JM, Newton AC, Diaz A, Bullock JM (2009) Enhancement of biodiversity and ecosystem services by ecological restoration. Science 325(28):1121-1124

Rosenthal A, Verutes G, McKenzie E, Arkema KK, Bhagabati N, Bremer LL, Olwero N, Vogl AL (2014) Process matters: a framework for conducting decision-relevant assessments of ecosystem services. Int J Biodivers Sci Ecosyst Serv Manag 11(3):90-204

Rost S, Gerten D, Bondeau A, Lucht W, Rohwer J, Schaphoff S (2008) Agricultural green and blue water consumption and its influence on the global water system. Water Resour Res 44:W09405

Rozzi R, Armesto JJ, Gutiérrez JR, Massardo F, Likens GE, Anderson CB, Poole A, Moses KP, Hargrove E, Mansilla AO, Kennedy JH, Willson M, Jax K, Jones GC, Callicott JB, Arroyo MTK (2012) Integrating ecology and environmental ethics: earth stewardship in the southern end of the Americas. Bioscience 62(3):226-236

Ruckelshaus M, McKenzie E, Tallis H, Guerry A, Daily G, Kareiva P, Polasky S, Ricketts T, Bhagabati N, Wood SA, Bernhardt J (2015) Notes from the field: lessons learned from using ecosystem service approaches to inform real-world decisions. Ecol Econ 115:11-21

Rusch A, Bommarco R, Jonsson M, Smith HG, Ekbom B (2013) Flow and stability of natural pest control services depend on complexity and crop rotation at the landscape scale. J Appl Ecol 50(2):345-354

Samnegård U, Persson AS, Smith HG (2011) Gardens benefit bees and enhance pollination in intensively managed farmland. Biol Cons 144:2602-2606

Schmidt MH, Lauer A, Purtauf T, Thies C, Schaefer M, Tscharntke $\mathrm{T}$ (2003) Relative importance of predators and parasitoids for cereal aphid control. Proc R Soc Lond B 270(1527):1905-1909

Schmidt A, Auge H, Brandl R, Heong KL, Hotes S, Settele J, Villareal S, Schädler M (2015a) Small-scale variability in the contribution of invertebrates to litter decomposition in tropical rice fields. Basic Appl Ecol 16:674-680

Schmidt A, John K, Arida G, Auge H, Brandl R, Horgan FG, Hotes S, Marques L, Radermacher N, Settele J, Wolters V, Schädler $\mathrm{M}$ (2015b) Effects of residue management on decomposition in irrigated rice fields are not related to changes in decomposer community structure. PLoS ONE 10(7):e0134402

Schmidt A, John K, Auge H, Brandl R, Horgan FG, Settele J, Zaitsev AS, Wolters V, Schädler M (2016) Compensatory mechanisms of litter decomposition under alternating moisture regimes in tropical rice fields. Appl Soil Ecol 107:79-90

Schoenly KG, Cohen JE, Heong KL, Litsinger JA, Barrion AT, Arida GS (2010) Fallowing did not disrupt invertebrate fauna in Philippine low-pesticide irrigated rice fields. J Appl Ecol 47:593-602

Scholte SSK, van Teeffelen AJA, Verburg PH (2015) Integrating sociocultural perspectives into ecosystem service valuation: a review of concepts and methods. Ecol Econ 114:67-78

Schulze CH, Waltert M, Kessler PJA, Pitopang R, Shahabuddin Veddeler D, Mühlenberg M, Gradstein SR, Leuschner C, SteffanDewenter I, Tscharntke T (2004) Biodiversity indicator groups of tropical land-use systems: comparing plants, birds, and insects. Ecol Appl 14(5):1321-1333

Seppelt R, Fath B, Burkhard B, Fisher JL, Grêt-Regamey A, Lautenbach S, Pert P, Hotes S, Spangenberg JH, Verburg PH, van Oudenhoven APE (2012) Form follows function? Proposing a blueprint for ecosystem service assessments based on reviews and case studies. Ecol Ind 21:145-154

Settele J, Kühn I, Klotz S, Arida G, Bergmeier E, Burkhard B, Bustamante JV, Truong Dao Thanh, Escalada M, Görg C, Grescho V, Van Chien Ho, Heong KL, Hirneisen N, Hotes S, Jahn R, Klotzbücher T, Marion G, Marquez L, Marxen A, Moritz R, Müller F, Van Sinh Nguyen, Ott J, Penev L, Rodriguez-Labajos B, Schädler M, Scheu S, Seppelt R, Stoev P, Tscharntke T, Tekken V, Thonicke K, Vetterlein D, Vidal S, Villareal S, Weisser WW, Westphal C, Wiemers M, Spangenberg JH (2013) Kulturlandschaftsforschung in Südostasien-das LEGATO-Projekt. Berichte Geographie und Landeskunde 87(3):315-323

Settele J, Spangenberg JH, Heong KL, Burkhard B, Bustamante JV, Cabbigat J, Chien HV, Escalada M, Grescho V, Hai LH, Harpke A, Horgan F, Hotes S, Jahn R, Kühn I, Marquez L, Schädler M, Tekken V, Vetterlein D, Villareal S, Westphal C, Wiemers M (2015) Agricultural landscapes and ecosystem services in SouthEast Asia-the LEGATO-project. Basic Appl Ecol 16:661-664

Settle WH, Ariawan H, Astuti ET, Cahyana W, Hakim AL, Hindayana D, Lestari AS (1996a) Managing tropical rice pests through conservation of generalist natural enemies and alternative prey. Ecology 77(7):1975-1988

Settle WH, Ariawan H, Astuti ET, Cahyana W, Lukman A, Hindayana D (1996b) Managing tropical rice pests through conservation of generalist natural enemies and alternative prey. Ecology 77:1975-1988

Siew TF, Aenis T, Spangenberg JH, Nauditt A, Frank S, RodriguezLabajos B, Ribbe L, Settele J, Wang J, Döll P (2016) Implementing transdisciplinary research in sustainable land management in China and Southeast Asia: challenges and adaptation strategies. Sustain Sci 11:813-829

Sitch S, Smith B, Prentice IC, Arneth A, Bondeau A, Cramer W, Kaplan JO, Levis S, Lucht W, Sykes MT, Thonicke K, Venevsky S (2003) Evaluation of ecosystem dynamics, plant geography and terrestrial carbon cycling in the LPJ dynamic global vegetation model. Glob Change Biol 9(2):161-185

Soliveres S, van der Plas F, Manning P, Prati D, Gossner MM, Renner SC, Alt F, Arndt H, Baumgartner V, Binkenstein J, Birkhofer K, Blaser S, Blüthgen N, Boch S, Böhm S, Börschig C, Buscot F, Diekötter T, Heinze J, Hölzel J, Jung K, Klaus VH, Kleinebecker T, Klemmer S, Krauss J, Lange M, Morri EK, Müller J, Oelmann Y, Overmann J, Pašalić E, Rillig MC, Schaefer HM, Schloter M, Schmitt B, Schöning I, Schrumpf M, Sikorski J, Socher SA, Solly EF, Sonnemann I, Sorkau E, Steckel J, Steffan-Dewenter I, Stempfhuber B, Tschapka M, Türke M, Venter PC, Weiner CN, Weisser WW, Werner M, Westphal C, Wilcke W, Wolters V, Wubet T, Wurst S, Fischer M, Allan E (2016) Biodiversity at multiple trophic levels is needed for ecosystem multifunctionality. Nature 536:456-459 
Spangenberg JH (2011) Sustainability science: a review, an analysis and some empirical lessons. Environ Conserv 38(3):275-287

Spangenberg JH (2014) Sustainability and the challenge of complex systems. In: Enders JC, Remig M (eds) Theories of sustainable development. Routledge, Abingdon, pp 89-111

Spangenberg JH, Settele J (2010) Precisely incorrect? Monetising the value of ecosystem services. Ecol Complex 7(3):327-337

Spangenberg JH, Settele J (2016) Value pluralism and economic valuation-defendable if well done. Ecosyst Serv 18:100-109

Spangenberg JH, Görg C, Truong DT, Tekken V, Bustamante JV, Settele J (2014a) Provision of ecosystem services is determined by human agency, not ecosystem functions. Four case studies. Int J Biodivers Sci Ecosyst Serv Manag 10(1):40-53

Spangenberg JH, von Haaren C, Settele J (2014b) The ecosystem service cascade: further developing the metaphor. Integrating societal processes to accommodate social processes and planning, and the case of bioenergy. Ecol Econ 104:22-32

Spangenberg JH, Douguet J-M, Settele J, Heong KL (2015a) Escaping the lock-in of continuous insecticide spraying in rice. Developing an integrated ecological and socio-political DPSIR analysis. Ecol Model 295:188-195

Spangenberg JH, Görg C, Settele J (2015b) Stakeholder involvement in ESS research and governance: between conceptual ambition and practical experiences-risks, challenges and tested tools. Ecosyst Serv 16:201-211

Spash CL (2008) How much is that ecosystem in the window? The one with the bio-diverse trail. Environ Values 17(2):259-284

Sukhdev P (2009) Costing the earth. Nature 462(7271):277

Syrbe R-U, Michel E (2013) Structural indicators for the assessment of biodiversity and their connection to the richness of avifauna. Ecol Ind 31:89-98

Tallis H, Lubchenco J, 238 co-signatories (2014) A call for inclusive conservation. Nature 515(7525):27-28

Tekken V, Settele J (2014) Instrumente zur nachhaltigen Agrarlandschafts-Optimierung: ecological Engineering als Ansatz zur Konstruktion nachhaltiger Agrarlandschaften in Reisanbaugebieten Südost-Asiens. In: Hartung G, Kirchhoff T (eds) Welche Natur brauchen wir? Analyse einer anthropologischen Grundproblematik des 21. Verlag Karl Alber, Freiburg, pp 173-186

Tekken V, Spangenberg JH, Escalada M, Burkhard B, Truong DT, Settele J (2017) "Things are different now": a qualitative assessment of farmer perceptions of cultural ecosystem services of traditional rice landscapes in Vietnam, and the Philippines. Ecosyst Serv 25:153-166

Tscharntke T, Bommarco R, Clough Y, Crist TO, Kleijn D, Rand TA, Tylianakis JM, van Nouhuys S, Vidal S (2007) Conservation biological control and enemy diversity on a landscape scale. Biol Control 43(3):294-309

Tscharntke T, Tylianakis JM, Rand TA, Didham RK, Fahrig L, Batary P, Bengtsson J, Clough Y, Crist TO, Dormann CF, Ewers RM, Fründ J, Holt RD, Holzschuh A, Klein AM, Kleijn D, Kremen C, Landis DA, Laurance W, Lindenmayer D, Scherber C, Sodhi
N, Steffan-Dewenter I, Thies C, van der Putten WH, Westphal C (2012) Landscape moderation of biodiversity patterns and processes—eight hypotheses. Biol Rev 87(3):661-685

Tsiafouli MA, Thébault E, Sgardelis SP, de Ruiter PC, van der Putten WH, Birkhofer K, Hemerik L, de Vries FT, Bardgett RD, Brady MV, Bjornlund L, Jørgensen HB, Christensen S, Hertefeldt TD, Hotes S, Hol WHG, Frouz J, Liiri M, Mortimer SR, Setälä H, Tzanopoulos J, Uteseny K, Pižl V, StaryJ Wolters V, Hedlund K (2015) Intensive agriculture reduces soil biodiversity across Europe. Glob Change Biol 21:973-985

Tylianakis JM, Tscharntke T, Lewis OT (2007) Habitat modification alters the structure of tropical host-parasitoid food webs. Nature 445:202-205

Václavík T, Lautenbach S, Kuemmerle T, Seppelt R (2013) Mapping global land system archetypes. Glob Environ Change 23(6): 1637-1647

Václavík T, Langerwisch F, Cotter M, Fick J, Häuser I, Hotes S, Kamp J, Settele J, Spangenberg JH, Seppelt R (2016) Investigating potential transferability of place-based research in land system science. Environ Res Lett 11(9):art 095002

van der Heijden MGA, Bardgett RD, van Straalen NM (2008) The unseen majority: soil microbes as drivers of plant diversity and productivity in terrestrial ecosystems. Ecol Lett 11:296-310

von Haaren C, Albert C (2011) Integrating ecosystem services and environmental planning: limitations and synergies. Int J Biodivers Sci Ecosyst Serv Manage 7(3):150-167

Wall DH, Nielsen UN (2012) Biodiversity and ecosystem services: is it the same below ground? Nat Educ Knowl 3(12):8

Walz U, Syrbe R-U (2013) Linking landscape structure and biodiversity. Ecol Ind 31:1-5

Way MJ, Heong KL (1994) The role of biodiversity in the dynamics and management of insect pests of tropical irrigated rice-a review. Bull Entomol Res 84(4):567-587

WBGU German Advisory Council on Global Change (2011) Flagship report: world in transition. A social contract for sustainability. WBGU, Berlin

Weichhardt P (2007) Humanökologie. Geographie. Physische Geographie und Humangeographie. In: Gebhardt H, Glaser R, Radtke U, Reuber P (eds) Spektrum Verlag, Heidelberg, pp 941-949

Werlen B (2000) Alltägliche Regionalisierungen unter räumlichzeitlich entankerten Lebensbedingungen. Informationen zur Raumentwicklung 9(10):611-622

Westphal C, Vidal S, Horgan FG, Gurr GM, Escalada M, Chien HV, Tscharntke T, Heong KL, Settele J (2015) Managing multiple ecosystem services with flower strips and participatory training in rice production landscapes. Basic Appl Ecol 16:681-689

Wöbse HH (2002) Landschaftsästhetik. Über das Wesen, die Bedeutung und den Umgang mit landschaftlicher Schönheit. Ulmer Verlag, Stuttgart

Wurst S (2010) Effects of earthworms on above- and belowground herbivores. Appl Soil Ecol 45:123-130

\section{Affiliations}

Joachim H. Spangenberg ${ }^{1,2}(1)$. Alexis L. Beaurepaire ${ }^{3}$ Erwin Bergmeier ${ }^{4} \cdot$ Benjamin Burkhard $^{5,6} \cdot$ Ho Van Chien $^{7}$. Le Quoc Cuong ${ }^{7}$. Christoph Görg ${ }^{8}$. Volker Grescho ${ }^{1,9}$. Le Huu Hai ${ }^{10} \cdot$ Kong Luen Heong $^{11,12}$ • Finbarr G. Horgan ${ }^{11}$. Stefan Hotes ${ }^{13}$. Anika Klotzbücher ${ }^{1,14}$. Thimo Klotzbücher ${ }^{14}$. Ingolf Kühn ${ }^{1,15,16}$. Fanny Langerwisch ${ }^{17}$. Glenn Marion ${ }^{18}$. Robin F. A. Moritz ${ }^{3,15}$. Quynh Anh Nguyen ${ }^{19}$. Jürgen Ott ${ }^{1,20}$. Christina Sann ${ }^{21}$. Cornelia Sattler ${ }^{1}$. Martin Schädler ${ }^{1}$. Anja Schmidt ${ }^{1}$. Vera Tekken ${ }^{22}$. Truong Dao Thanh ${ }^{19} \cdot$ Kirsten Thonicke $^{17} \cdot$ Manfred Türke $^{16,23,24}$. Tomáš Václavík $^{25,26} \cdot$ Doris Vetterlein ${ }^{14,27} \cdot$ Catrin Westphal ${ }^{28} \cdot$ Martin Wiemers $^{1} \cdot$ Josef Settele ${ }^{1,16,29}$ 
1 Department of Community Ecology, UFZ - Helmholtz Centre for Environmental Research, Theodor-Lieser-Str. 4, 06120 Halle, Germany

2 Sustainable Europe Research Institute SERI Germany e.V., Vorsterstr. 97-99, 51103 Cologne, Germany

3 Institute of Biology, Martin-Luther-University Halle/Wittenberg, Hoher Weg 4, 06099 Halle/Saale, Germany

4 Albrecht von Haller Institute of Plant Sciences, Georg August University Göttingen, Untere Karspüle 2, 37073 Göttingen, Germany

5 Institute for Natural Resource Conservation, Kiel University, Olshausenstraße 40, 24098 Kiel, Germany

6 Leibniz Centre for Agricultural Landscape Research ZALF, Eberswalder Str. 84, 15374 Müncheberg, Germany

7 Southern Regional Plant Protection Center, Ministry of Agriculture and Rural Development Vietnam, Long Dinh, Tien Giang, Vietnam

8 Institute of Social Ecology, University of Klagenfurt, Schottenfeldgasse 29, 1070 Vienna, Austria

9 OLANIS GmbH, Pittlerstraße 33, 04159 Leipzig, Germany

10 Tien Giang University, My Tho, Tien Giang, Vietnam

11 University of Technology Sydney, 15 Broadway, Ultimo, Sydney, NSW 2007, Australia

12 Zhejiang University, Hangzhou, People's Republic of China

13 Department of Ecology, Animal Ecology, Philipps-University Marburg, Karl-v.-Frisch-Str. 8, 35043 Marburg, Germany

14 Chair of Soil Science, Martin-Luther-University Halle-Wittenberg, Von-Seckendorff-Platz 3, 06120 Halle, Germany

15 Geobotany and Botanical Garden, Martin-Luther-University Halle-Wittenberg, Am Kirchtor 1, 06108 Halle, Germany

16 German Centre for Integrative Biodiversity Research (iDiv), Halle-Jena-Leipzig, Deutscher Platz 5e, 04103 Leipzig, Germany
17 Potsdam Institute for Climate Impact Research (PIK), Earth System Analysis, Telegrafenberg A31, 14473 Potsdam, Germany

18 Biomathematics and Statistics Scotland, James Clerk Maxwell Building, Peter Guthrie Tait Road, Edinburgh EH9 3FD, UK

19 Institute of Policy and Management (IPAM), VNU-University of Social Sciences and Humanities, No. 336, Nguyen Trai Street, Thanh Xuan Dist., Hanoi, Vietnam

20 L.U.P.O. GmbH, Friedhofstrasse 28, 67705 Trippstadt, Germany

21 Agroentomology, Georg-August University Göttingen, Grisebachstrasse 6, 37077 Göttingen, Germany

22 Ernst-Moritz-Arndt-University Greifswald, Friedrich-Ludwig-Jahn-Str. 16, 17487 Greifswald, Germany

23 Terrestrial Ecology Research Group, Department of Ecology and Ecosystem Management, Technical University Munich, Hans-Carl-von-Carlowitz-Platz 2, 85354 Freising, Germany

24 Institute of Biology, Leipzig University, Johannisallee 21, 04103 Leipzig, Germany

25 Department of Computational Landscape Ecology, UFZ - Helmholtz Centre for Environmental Research, Permoserstr. 15, 04318 Leipzig, Germany

26 Department of Ecology and Environmental Sciences, Faculty of Science, Palacký University Olomouc, Šlechtitelů 27, 78371 Olomouc, Czech Republic

27 Department of Soil Physics, UFZ - Helmholtz Centre for Environmental Research, Theodor-Lieser-Str. 4, 06120 Halle, Germany

28 Agroecology, Department of Crop Sciences, Georg-August University Göttingen, Grisebachstrasse 6, 37077 Göttingen, Germany

29 Institute of Biological Sciences, University of the Philippines Los Baños, College, 4031 Los Baños, Laguna, Philippines 